\title{
Fullerene-Based Materials for Photovoltaic Applications: Toward Efficient, Hysteresis-Free, and Stable Perovskite Solar Cells
}

Lin-Long Deng, Su-Yuan Xie and Feng Gao

The self-archived postprint version of this journal article is available at Linköping University Institutional Repository (DiVA):

http:/ / urn.kb.se/ resolve?urn=urn:nbn:se:liu:diva-152395

N.B.: When citing this work, cite the original publication.

Deng, L., Xie, S., Gao, F., (2018), Fullerene-Based Materials for Photovoltaic Applications: Toward Efficient, Hysteresis-Free, and Stable Perovskite Solar Cells, ADVANCED ELECTRONIC MATERIALS, 4(10), 1700435. https:// doi.org/ 10.1002/ aelm.201700435

Original publication available at:

https:// doi.org/ 10.1002/ aelm.201700435

Copyright: Wiley (12 months)

http:/ / eu.wiley.com/WileyCDA/ 


\section{WILEY-VCH}

DOI: 10.1002/ ((please add manuscript number))

\section{Article type: Progress Report}

Fullerene-based Materials for Photovoltaic Applications: Towards Efficient, Hysteresisfree, and Stable Perovskite Solar Cells

Lin-Long Deng, Su-Yuan Xie, * and Feng Gao*

Dr. L. L. Deng

Pen-Tung Sah Institute of Micro-Nano Science and Technology,

Xiamen University, Xiamen 361005, China

Prof. S. Y. Xie

State Key Lab for Physical Chemistry of Solid Surfaces,

iChEM (Collaborative Innovation Center of Chemistry for Energy Materials),

Department of Chemistry, College of Chemistry and Chemical Engineering,

Xiamen University, Xiamen 361005, China

E-mail: syxie@xmu.edu.cn

Dr. F. Gao

Department of Physics, Chemistry, and Biology (IFM)

Linköping University, Linköping SE-581 83, Sweden

E-mail: fenga@ifm.liu.se

Keywords: perovskite solar cells, fullerenes, efficiency, hysteresis, stability

Abstract: Perovskite solar cells are promising candidates for next-generation photovoltaics.

Fullerenes and their derivatives can act as efficient electron transport layers, interfacial

modification layers and/or trap state passivators in perovskite solar cells, which play an important role in increasing efficiency, reducing current hysteresis, and enhancing device

stability. Herein, recent progresses of fullerenes and their derivatives used in perovskite solar cells are reviewed, with a particular emphasis on fullerene chemical structures that affect performance of the devices. Potential candidates of fullerenes that could further improve device performance and stability are also discussed. 


\section{WILEY-VCH}

\section{Introduction}

Organic-inorganic hybrid perovskite solar cells (PSCs) have received considerable attention as a cost-effective alternative to conventional solar cells because of their pivotal advantages of high efficiency and low cost. ${ }^{[1-5]}$ The light-absorbing perovskites can be represented by the general formula $\mathrm{ABX}_{3}\left(\mathrm{~A}=\mathrm{CH}_{3} \mathrm{NH}_{3}{ }^{+}, \mathrm{CH}\left(\mathrm{NH}_{2}\right)_{2}{ }^{+}\right.$, $\mathrm{Cs}^{+}$, etc.; $\mathrm{B}=\mathrm{Pb}^{2+}, \mathrm{Sn}^{2+}$, etc.; $\mathrm{X}=\mathrm{I}^{-}, \mathrm{Br}^{-}$, $\left.\mathrm{Cl}^{-}\right){ }^{[6,7]}$ which adopt the $\mathrm{ABX}_{3}$ perovskite structures (Figure 1a). Perovskite materials have excellent optoelectronic properties, such as high absorption coefficient, high carrier mobility, and long carrier diffusion length. ${ }^{[1,8-12]}$ Benefiting from these merits, the power conversion efficiency (PCE) of PSCs has increased from 3.8\% to $22.1 \%$ in the past few years, ${ }^{[13-21]}$ approaching that of commercialized solar cells, such as polycrystalline silicon, cadmium telluride (CdTe) and copper indium gallium diselenide (CIGS). PSCs are classified into two main device architectures: mesoscopic and planar heterojunction structures (Figure 1b). The planar structure can be further divided into two categories, that is, the planar n-i-p structure and the inverted planar p-i-n structure, depending on the position of the electron or hole transport layer (ETL/HTL). To date, high efficiency PSCs have been demonstrated for both mesoscopic and planar structures.

\section{Figure 1.}

Although significant progress has been made in the development of PSC, they still face many challenges including toxicity, instability and hysteresis. ${ }^{[22-26]}$ One disadvantage of PSCs is the use of toxic lead. To overcome the toxicity of lead containing PSCs, a range of lead-free perovskite solar cells have been developed. ${ }^{[27-29]}$ However, their efficiencies are still very low compared to those of lead-based PSCs. Another major drawback of PSCs is the inherent instability of perovskites, which degrade rapidly under ambient atmosphere, UV illumination, or elevated temperature. ${ }^{[25,30]}$ Several possible approaches to improving the stability of PSCs 


\section{WILEY-VCH}

have been developed, including perovskite material modification, low dimensional perovskites, interface engineering, additive engineering, encapsulation, etc. ${ }^{[31-39]}$ Hysteresis in the current-voltage $(J-V)$ curves is another notorious problem for PSCs. ${ }^{[23,40]}$ The possible origination of hysteresis may come from the perovskite itself or the interfaces between perovskites and charge collection layers. ${ }^{[40,41]}$ The hysteresis of perovskite solar cells can be reduced or even eliminated by passivating the interfacial charge trap states or reducing the mobile ionic species within perovskites. ${ }^{[40,41]}$

Since the discovery of fullerenes in $1985,{ }^{[42]}$ they have been extensively investigated because of their unique structural and electronic properties. Fullerenes have many unique and fascinating features, such as high electron affinity, ${ }^{[43]}$ small reorganization energy, ${ }^{[44-46]}$ high electron mobility, ${ }^{[47-50]}$ etc. Because of the fantastic properties of fullerenes and their wellmatched energy levels with perovskites, fullerene-based materials have been widely employed in PSCs, acting as electron transport materials, interfacial modification materials, or trap state passivators within the perovskite light-absorbing layer.

Recently, several reviews have summarized the applications and roles of fullerene derivatives in PSCs, and discussed the mechanism of fullerenes for trap state passivation, reducing hysteresis as well as enhancing device performance. ${ }^{[51-53]}$ Fullerenes can effectively passivate the trap states at the surfaces and grain boundaries of the perovskite layer, relating to the formation of fullerene-halide radicals that suppress the formation of deep trap states. The passivation effect of fullerenes as well as the efficient electron transfer between perovskites and fullerenes could contribute to the reduced hysteresis and enhanced performance of fullerene-based devices. Furthermore, fullerenes can suppress the ion diffusion in perovskites owing to the filling of perovskite grain boundaries by the large-sized fullerenes, which could also be another reason for the much smaller hysteresis of fullerenebased devices. However, the relationship between the chemical structures of fullerenes and their photovoltaic properties has been hardly discussed. Chemical tailoring of fullerenes is 


\section{WILEY-VCH}

needed for their applications in PSCs for enhanced efficiency, reduced hysteresis, and improved stability.

In this review, we highlight the recent progresses of fullerene materials in PSCs and address the influence of their chemical structures on photovoltaic performance. In view of the different roles of fullerenes in PSCs, our discussion will be divided into three topics: fullerene electron transport layers, fullerene-based interlayers, and perovskite-fullerene heterojunctions. We hope that this review will provide valuable insights for the rational design of fullerene materials with suitable properties for better solar cell applications.

\section{Fullerene electron transport layer for the p-i-n structure}

In 2013, Chen and co-workers have pioneered the use of fullerene $\mathrm{C}_{60}$ and its derivatives [6,6]-phenyl $\mathrm{C}_{61}$-butyric acid methyl ester $\left(\mathrm{PC}_{61} \mathrm{BM}\right)$ or indene- $\mathrm{C}_{60}$ bisadduct $\left(\mathrm{IC}_{60} \mathrm{BA}\right)$ as the electron transport layer in p-i-n PSCs (Figure 2a). ${ }^{[54]}$ The molecular structures of $\mathrm{PC}_{61} \mathrm{BM}$ and $\mathrm{IC}_{60} \mathrm{BA}$ are depicted in Figure 3. The lowest unoccupied molecular orbital (LUMO) energy levels of $\mathrm{C}_{60}$ or $\mathrm{PC}_{61} \mathrm{BM}$ match well with the conduction band of perovskite material, enabling efficient charge separation at the perovskite-fullerene interfaces (Figure 2b). Although the power conversion efficiency (PCE) was low (3.9\%), their work demonstrated the feasibility of fullerene materials as the ETL for p-i-n PSCs. A higher PCE of 7.4\% was achieved by employing a thicker $\mathrm{CH}_{3} \mathrm{NH}_{3} \mathrm{PbI}_{3}$ layer with the $\mathrm{PC}_{61} \mathrm{BM}$ ETL. ${ }^{[55]}$ Later on, the use of $[6,6]$-phenyl $\mathrm{C}_{71}$-butyric acid methyl ester $\left(\mathrm{PC}_{71} \mathrm{BM}\right)$ to replace $\mathrm{PC}_{61} \mathrm{BM}$ as the ETL, was demonstrated to further increase the PCE from $9.92 \%$ to $16.31 \%$, mainly due to an increase in short-circuit current density $\left(J_{\mathrm{sc}}\right) .{ }^{[56]}$ Notably, $\mathrm{PC}_{71} \mathrm{BM}$ is a mixture of three isomers. To investigate the isomer-dependent photovoltaic performance of $\mathrm{PC}_{71} \mathrm{BM}$-based PSCs, Xie and co-workers isolated PC ${ }_{71} \mathrm{BM}$ into three typical isomers of $\alpha-, \beta_{1}$ - and $\beta_{2}$ $\mathrm{PC}_{71} \mathrm{BM}$ (Figure 3). ${ }^{[57]}$ Different ternary compositions of $\mathrm{PC}_{71} \mathrm{BM}$ isomers were blended as the ETLs to fabricate PSCs with PCE in the range of 0.38-17.56\% due to different molecular 


\section{WILEY-VCH}

aggregation of $\mathrm{PC}_{71} \mathrm{BM}$ isomers. They found that mixed $\mathrm{PC}_{71} \mathrm{BM}\left(\alpha: \beta_{1}: \beta_{2}=17: 1: 2\right)$ represents the best ETL superior to either each of the purified isomers or any other ternary isomers of $\mathrm{PC}_{71} \mathrm{BM}$. In 2015, several groups adopted different film deposition methods to obtain high quality perovskite films, which further increased the PCE of $\mathrm{CH}_{3} \mathrm{NH}_{3} \mathrm{PbI}_{3} / \mathrm{PC}_{61} \mathrm{BM}$ based device to $~ 18 \%{ }^{[58-60]}$

Understanding the functions of fullerene layers is very important. In 2014, Huang et al. employed a unique double fullerene layers as the electron extraction layer, boosting the fill factor (FF) to above $80 \%$ and PCE to $12.2 \%{ }^{[61]}$ The double fullerene layers were formed by spin-coating $\mathrm{PC}_{61} \mathrm{BM}$ or $\mathrm{IC}_{60} \mathrm{BA}$ layer on top of a thermal evaporated $\mathrm{C}_{60}$ layer. The adoption of double fullerene layers can dramatically reduce dark current leakage by forming a Schottky junction with the anode, and effectively passivate charge traps in the perovskite film. Later on, they demonstrated that fullerene layers deposited on the top of perovskites can effectively passivate the charge trap states on the surface and grain boundaries of the perovskite materials (Figure 2c), and eliminate the notorious hysteresis in the $J$ - $V$ curves. ${ }^{[62]}$ Their work illustrates that fullerene materials not only function as the ETL, but also act as trap state passivator of perovskites which can effectively passivate the trap states of perovskite and eliminate the notorious $J$ - $V$ hysteresis.

\section{Figure 2.}

\section{Figure 3.}

In order to elucidate the correlation between fullerene ETLs and the resulting device performance, several groups have systematically investigated the factors that influence device performance, such as electron mobility, film morphology, and structural order etc. For instance, Jen et al. systematically studied the influence of electron mobility of fullerene-based 


\section{WILEY-VCH}

ETLs on the photovoltaic performance. ${ }^{[63]}$ The PCE of IC ${ }_{60} \mathrm{BA}, \mathrm{PC}_{61} \mathrm{BM}$, and $\mathrm{C}_{60}$-based devices is $8.06 \%, 13.37 \%$, and $15.44 \%$, respectively, which follows the trend of increased electron mobility in the fullerene layer. Their work clearly illustrated that high electron mobility fullerenes could effectively promote charge dissociation/transport in PSCs and enhance photovoltaic performance. Xie and co-workers further investigated the effects of charge-transporting, and film-forming properties of fullerene-based ETLs on the resulting photovoltaic performance. ${ }^{[64]}$ Three $\mathrm{C}_{60}$ derivatives, EDNC, BDNC, and $\mathrm{PC}_{61} \mathrm{BM}$ (Figure 3) were introduced into p-i-n PSCs as ETLs. Because of better surface morphology, the EDNCbased device exhibited higher PCE (12.64\%) than that of BDNC-based device (7.36\%) despite of their similar LUMO energy level, electron mobility, and optical properties. The electronic mobility of $\mathrm{PC}_{61} \mathrm{BM}$ was approximately one order of magnitude higher than that of EDNC, leading to higher PCE for $\mathrm{PC}_{61} \mathrm{BM}$-based device (15.04\%). Their work demonstrates the importance of electron mobility and surface morphology of fullerene-based ETLs on device performance. Recently, Huang et al. reported a simple solvent annealing method to reduce the disorder in the PC ${ }_{61} \mathrm{BM}$ ETL (Figure 4a), which enhanced the PCE to $19.4 \%$ due to the enhancement in open-circuit voltage $\left(V_{\mathrm{oc}}\right) .{ }^{[65]}$ The wide distributed electronic density of states (DOS) caused by the energy disorder of the $\mathrm{PC}_{61} \mathrm{BM}$ layer can reduce the quasi-Fermi level of the photo-generated electrons and thus reduce the device $V_{\text {ос }}$ (Figure $4 \mathrm{~b}$ ). The $V_{\text {oc }}$ of the device was enhanced from 1.04 to $1.13 \mathrm{~V}$ by reducing the structural disorder of $\mathrm{PC}_{61} \mathrm{BM}$, without sacrificing the $J_{\mathrm{sc}}$ and FF. Their work shows that the structural order of the fullerene ETLs also has a significant impact on photovoltaic performance.

\section{Figure 4.}

In addition to $\mathrm{PC}_{61} \mathrm{BM}$ and $\mathrm{PC}_{71} \mathrm{BM}$, a large number of other fullerene derivatives have also been synthesized and employed as ETLs in p-i-n PSCs to improve device performance 


\section{WILEY-VCH}

and stability. To passivate perovskite trap states and reduce the work function of the metal cathode, a new series of hydrophilic fullerene derivatives with electron-rich oligoether (OE) chains (Figure 3) was designed as ETLs for p-i-n PSCs. ${ }^{[66]}$ Devices based on $\mathrm{C}_{60} / \mathrm{C}_{70}$ derivative ETLs with OE chains exhibited significant improvement in PCE compared to devices with $\mathrm{PC}_{61} \mathrm{BM}$ or $\mathrm{PC}_{71} \mathrm{BM}$ ETLs. The best device based on $\mathrm{C}_{70}$-DPM-OE showed PCE of $16 \%$, which is higher than that of the device with the PC ${ }_{71}$ BM ETL. To eliminate the light-soaking phenomenon in PSCs, a fulleropyrrolidine with a hydrophilic triethylene glycol monoethyl ether side chain (PTEG-1) (Figure 3) was employed as the ETL. ${ }^{[67]}$ Compared to the commonly used PC 61 BM ETL, PTEG-1 has identical energy levels but a higher dielectric constant (5.9 vs 3.9). Devices based on PTEG-1 showed a negligible light soaking effect, with a PCE of $15.2 \%$ before light soaking and a minor increase to $15.7 \%$ after light soaking. However, devices based on $\mathrm{PC}_{61} \mathrm{BM}$ exhibited severe light soaking, with the PCE improving from $3.8 \%$ to $11.7 \%$. The elimination of light-soaking is attributed to the high dielectric constant and electron donating properties of PTEG-1, which helps to suppress the trapassisted recombination at the perovskite/PTEG-1 interfaces.

To increase the $V_{\text {oc }}$ of fullerene-based PSCs, fullerene derivatives with high-lying LUMO energy levels have been developed and used as ETLs in p-i-n PSCs. For instance, five fullerene derivatives (Figure 3) were evaluated as ETLs in p-i-n PSCs. ${ }^{[68]}$ Devices based on indene fullerene (IPB or IPH) exhibited higher $V_{\text {oc }}$ and PCE than those of devices based on methanofullerene ( $\mathrm{PC}_{61} \mathrm{BM}, \mathrm{PC}_{61} \mathrm{BH}$, or $\left.\mathrm{PC}_{61} \mathrm{BB}\right)$, which is related to higher $\mathrm{LUMO}$ energy levels of indene fullerenes. A indene fullerene bisadduct, $\mathrm{C}_{60}\left(\mathrm{CH}_{2}\right)$ (Ind) (Figure 3), with high-lying LUMO energy levels was introduced to replace $\mathrm{PC}_{61} \mathrm{BM}$ as the ETL in PSCs for maximizing the voltage output. ${ }^{[69]}$ Compared with $\mathrm{PC}_{61} \mathrm{BM}, \mathrm{C}_{60}\left(\mathrm{CH}_{2}\right)(\mathrm{Ind})$ possesses a slightly lower electron mobility but a higher LUMO energy levels (-3.66 eV vs $-3.8 \mathrm{eV})$. The $V_{\text {oc }}$ and PCE increased from $1.05 \mathrm{~V}$ and $16.2 \%$ to $1.13 \mathrm{~V}$ and $18.1 \%$ when $\mathrm{PC}_{61} \mathrm{BM}$ was replaced by $\mathrm{C}_{60}\left(\mathrm{CH}_{2}\right)$ (Ind). 


\section{WILEY-VCH}

To further increase the $V_{\text {oc }}$ of fullerene-based PSCs, devices with large bandgap perovskites as absorbers and fullerene derivatives with high-lying LUMO energy levels as ETLs are fabricated. For instance, PSCs with $\mathrm{CH}_{3} \mathrm{NH}_{3} \mathrm{PbBr}_{3}\left(\mathrm{MAPbBr}_{3}\right)$ as absorber and $\mathrm{IC}_{60} \mathrm{BA}$ as the ETL were fabricated. ${ }^{[70]}$ The conduction band of $\mathrm{CH}_{3} \mathrm{NH}_{3} \mathrm{PbBr}_{3}$ is $c a .0 .5 \mathrm{eV}$ higher than that of $\mathrm{CH}_{3} \mathrm{NH}_{3} \mathrm{PbI}_{3}$ and $\mathrm{PC}_{61} \mathrm{BM}$. Therefore, $\mathrm{IC}_{60} \mathrm{BA}$ was chosen because the LUMO energy level of $\mathrm{IC}_{60} \mathrm{BA}$ was $c a .0 .2 \mathrm{eV}$ higher than that of $\mathrm{PC}_{61} \mathrm{BM}$. Devices based on $\mathrm{CH}_{3} \mathrm{NH}_{3} \mathrm{PbBr}_{3} / \mathrm{IC}_{60} \mathrm{BA}$ exhibited a remarkably high $V_{\text {oc }}$ of $1.61 \mathrm{~V}$. Similar results were also obtained with wide-bandgap $(\mathrm{WBG})$ perovskite $\left(\mathrm{FA}_{0.83} \mathrm{MA}_{0.17}\right)_{0.95} \mathrm{Cs}_{0.05} \mathrm{~Pb}_{0.6}\left(\mathrm{I}_{0.6} \mathrm{Br}_{0.4}\right)_{3}(\mathrm{FA}=$ $\left.\mathrm{HC}\left(\mathrm{NH}_{2}\right)_{2}\right)$ as absorber and $\mathrm{IC}_{60} \mathrm{BA}$ as the ETL. ${ }^{[71]}$ The WBG PSCs with the IC ${ }_{60} \mathrm{BA}$ ETL showed a slightly improved $V_{\text {oc }}$ by $20 \mathrm{mV}$ on average than those with the PC ${ }_{61} \mathrm{BM}$ ETL. Since $\mathrm{IC}_{60} \mathrm{BA}$ is a mixture of structural isomers which is the origin of large energy disorder, $\mathrm{IC}_{60} \mathrm{BA}$-tran3 isomer (Figure 3) was further isolated from $\mathrm{IC}_{60} \mathrm{BA}$-mixture to reduce the energy disorder. $\mathrm{IC}_{60} \mathrm{BA}$-tran3 showed the same high-lying LUMO level, but much smaller energy disorder and much larger conductivity compared to the $\mathrm{IC}_{60} \mathrm{BA}$-mixture. WBG PSCs with IC ${ }_{60}$ BA-tran3 yielded a high $V_{\text {oc }}$ of $1.21 \mathrm{~V}$ and enhanced PCE up to $18.5 \%$.

The instability of PSCs is a major challenge to be addressed before practical applications of PSCs. To enhance the stability of PSCs, hydrophobic fullerene derivatives have been explored in p-i-n PSCs. A new fullerene derivative C5-NCMA (Figure 3) was designed to replace the commonly used $\mathrm{PC}_{61} \mathrm{BM}$ as ETLs in p-i-n PSCs. ${ }^{[72]}$ Compared with $\mathrm{PC}_{61} \mathrm{BM}$, C5-NCMA has a higher hydrophobicity, higher LUMO energy level and higher ability of self-assembly. Devices based on C5-NCMA showed PCE of $17.6 \%$ with negligible hysteresis, which is higher than that of $\mathrm{PC}_{61} \mathrm{BM}$ (16.1\%). Moreover, the hydrophobic C5-NCMA can efficiently prevent the moisture penetration into the perovskite layer, which significantly enhanced the device stability to moisture. Fullerene derivative isobenzofulvene- $\mathrm{C}_{60}$-epoxide (IBF-Ep, Figure 3) was used as ETLs in both normal and inverted PSCs. ${ }^{[73]}$ Compared to PC 61 BM, IBF-Ep has superior morphological stability under thermal stress, which results from the 


\section{WILEY-VCH}

bulky epoxidized isobenzofulvene group that helps to suppress solid state phase transitions. Inverted devices with IBF-Ep as ETLs exhibited a PCE of 9.0\% with superior tolerance to high humidity (90\%) in air. Two hydrophobic fulleropyrrolidine derivatives, DMEC60 and DMEC $_{70}$ (Figure 3), were used as ETLs in p-i-n PSCs. ${ }^{[74]}$ Possibly due to the attached pyrrolidine ester groups that are able to coordinate with the perovskite layer, devices based on $\mathrm{DMEC}_{60}$ and $\mathrm{DMEC}_{70}$ exhibited PCEs of $15.2 \%$ and $16.5 \%$, respectively, which were higher than those of devices based on $\mathrm{PC}_{61} \mathrm{BM}(14.5 \%)$ and $\mathrm{PC}_{71} \mathrm{BM}$ (15.1\%). The stability of the devices was also improved when DMEC $60_{60}$ and DMEC $_{70}$ were used as the ETLs, due to slightly hydrophobic pyrrolidine group on DMEC $60_{60}$ and DMEC 70 . Recently, a dimeric fullerene derivative (D-C 60 , Figure 3) was applied as ETLs in PSCs. ${ }^{[75]}$ Compared with $\mathrm{PC}_{61} \mathrm{BM}, \mathrm{D}-\mathrm{C}_{60}$ can efficiently passivate the trap states between the perovskite and fullerene layers, leading to improved electron extraction and photovoltaic performance. Devices based on D-C 60 exhibited PCE of 16.6\%, which is higher than that of $\mathrm{PC}_{61} \mathrm{BM}$ (14.7\%). In addition, the more hydrophobic and compact D-C 60 layer resulted in higher device stability than that with $\mathrm{PC}_{61} \mathrm{BM}$.

To simultaneously enhance the stability and efficiency of p-i-n PSCs, Huang et al. employed crosslinkable silane-functionalized and doped fullerene as the ETL. ${ }^{[76]}$ Crosslinkable silane molecules with hydrophobic functional groups are bonded onto $\mathrm{C}_{60}$ substituted benzoic acid self-assembled monolayer ( $\mathrm{C}_{60}$-SAM, Figure 3 ) to make the fullerene layer highly water-resistant. Notably, a relatively thick fullerene layer is needed to enhance the water resistivity, while the larger thickness and cross-linking process can inevitably increase the device contact resistance. To improve the electron conductivity of the crosslinked $\mathrm{C}_{60}$-SAM ETL, methylammonium iodide (MAI) was introduced as the n-type dopant. With crosslinkable silane-functionalized and doped fullerene as the ETL, PSCs exhibited PCE of $19.5 \%$ without photocurrent-hysteresis. More importantly, these devices retained nearly $90 \%$ of their original high efficiency after exposing to an ambient environment for 30 days. 


\section{WILEY-VCH}

The above-mentioned molecular structures of fullerene ETLs for p-i-n PSCs are summarized in Figure 3 and the corresponding photovoltaic parameters are presented in Table 1. These works demonstrate that factors such as LUMO energy level, electron mobility, surface morphology, hydrophobicity, and structural order of fullerenes should be considered in the molecular design of fullerene ETLs for efficient and stable p-i-n PSCs. The energy level matching between the conduction band of the perovskite layer and the LUMO of fullerene ETL is important to obtain high $V_{\text {oc. }}$ For instance, devices based on fullerene ETL with high-lying LUMO exhibit slightly higher $V_{\text {oc }}$. Besides LUMO energy level, the structural order of fullerene ETL has a significant effect on the $V_{\text {oc. }}$. Higher electron mobility and better surface morphology of fullerene ETL can contribute to higher $J_{\text {sc }}$ and FF. The hydrophobicity of fullerene ETL significantly affects the device stability.

All these factors are determined by the chemical structure and self-aggregation of fullerenes, which needs to be further optimized for practical applications of p-i-n PSCs. The LUMO energy level, electron mobility, surface morphology, and hydrophobicity of fullerene ETL are determined by the fullerene core, the functional group and the number of addends. For instance, $\mathrm{C}_{70}$ derivative has similar LUMO energy level but slightly lower electron mobility compared with its $\mathrm{C}_{60}$ counterpart. However, devices based on $\mathrm{C}_{70}$ derivative has better performance than that of $\mathrm{C}_{60}$ derivative, which is probably due to better perovskite/ $\mathrm{C}_{70}$ derivative interfacial contact. For $\mathrm{C}_{60}$ derivative, indene fullerene has slightly higher LUMO energy level that that of methanofullerene, leading to slightly higher $V_{\text {oc }}$ of device based on the indene fullerene ETL. The functional group determines the hydrophobicity of fullerene ETL. For instance, fullerene ETL with hydrophobic functional groups can block the moisture penetration into the perovskite layer and improve the device stability. Generally, the bisadduct fullerene has higher LUMO energy level than that of mono-adduct fullerene. Thus, device based on $\mathrm{IC}_{60} \mathrm{BA}$ ETL has a higher $V_{\text {oc }}$ than that of $\mathrm{PC}_{61} \mathrm{BM}$ ETL, but the $V_{\text {oc }}$ enhancement is much less than the LUMO difference. Notably, fullerene bisadduct or 


\section{WILEY-VCH}

multiadduct is a mixture of a variety of isomers and each isomer has different degree of energy disorder. Therefore, to obtain higher $V_{\text {oc }}$ and PCE, it is desirable to isolate the isomer mixture and find the isomer with the smallest energy disorder, which is exemplified by $\mathrm{IC}_{60} \mathrm{BA}$. From the above discussion, it is envisioned that further investigation on optimization of the fullerene core, the function groups, the number of addends, and regioisomer etc. will increase both the device efficiency and stability of PSCs.

Table 1.

\section{Fullerene cathode buffer layer for the p-i-n structure}

For p-i-n PSCs, $\mathrm{PC}_{61} \mathrm{BM}$ is the most popular ETL. However, recent studies show that $\mathrm{PC}_{61} \mathrm{BM}$ itself cannot fully form a perfect ohmic contact with metal electrodes such as $\mathrm{Al}$ or Ag. ${ }^{[51,52]}$ Therefore, several cathode buffer layers (CBLs), such as bathocuproine (BCP), ${ }^{[54]}$ $\mathrm{TiO}_{x},{ }^{[77]} \mathrm{LiF}^{[78]} \mathrm{PFN},{ }^{[79]} \mathrm{ZnO},{ }^{[80]}$ and $\mathrm{C}_{60} / \mathrm{LiF}^{[81]}$ were inserted between $\mathrm{PC}_{61} \mathrm{BM}$ and metal electrode to further improve the ohmic contact. Nevertheless, most of the above-mentioned cathode buffer layers have to be prepared using vacuum deposition or fabricated with complicated fabrication processes. By contrast, fullerene-based cathode buffer layers have attracted much attention because of their advantages such as chemical tunability and solution processability.

Fullerene derivatives with polar functional groups including oligoether and crown-ether have been developed as CBLs in p-i-n PSCs. For instance, a fullerene derivative with oligoether side chains (Bis-C 60 ) (Figure 5) was employed as an efficient electron-selective interfacial layer between $\mathrm{PC}_{61} \mathrm{BM}$ and $\mathrm{Ag}$ electrode to align the energy levels at $\mathrm{PC}_{61} \mathrm{BM} / \mathrm{Ag}$ interface and provide environmental stability. ${ }^{[82]}$ To further enhance the ambient stability of pi-n PSCs, a novel C60 $_{60}$ derivative F-C60 (Figure 5) with a perfluoroalkyl side-chain was synthesized. ${ }^{[83]}$ By blending F-C 60 with bis- $\mathrm{C}_{60}$ to form a hybrid cathode interlayer between 


\section{WILEY-VCH}

$\mathrm{PC}_{61} \mathrm{BM}$ and $\mathrm{Ag}$ cathode, it simultaneously enhanced the photovoltaic performance and ambient stability of PSCs. The long hydrophobic perfluoroalkyl side-chains on F-C60 can effectively prevent moisture penetration into the perovskite films, which dramatically improved the air stability of PSCs. A crown-ether functionalized fullerene PCBC (Figure 5) was synthesized and applied as CBLs in p-i-n PSCs. ${ }^{[84]}$ The introduction of the PCBC CBL can improve the interfacial ohmic contact between $\mathrm{PC}_{61} \mathrm{BM}$ and the $\mathrm{Al}$ electrode, which greatly enhanced the device performance to $15.08 \%$.

Amine functionalized fullerene derivatives have also been extensively investigated in p-i-n PSCs as CBLs because the amine group can form an interfacial dipole layer that can reduce the work function of metal electrode and facilitate ohmic contact at ETL/metal electrode interfaces. For instance, an amine functionalized fullerene derivative DMAPA-C 60 (Figure 5) was used as a dipolar cathode buffer layer for p-i-n PSCs. ${ }^{[85]}$ The formation of an interfacial dipole layer by DMAPA-C60 layer can reduce the work function of Ag electrode and facilitate a selective quasi-ohmic contact at $\mathrm{PC}_{61} \mathrm{BM} / \mathrm{Ag}$ interfaces, which greatly improved the $\mathrm{FF}$ to 77\% and PCE to $13.4 \%$. A fulleropyrrolidine with amine substitutent $\left(\mathrm{C}_{60}-\mathrm{N}\right)$ (Figure 5) was employed as cathode buffer layer between Ag electrode and PC ${ }_{61} B M$ ETL. ${ }^{[86]}$ The $\mathrm{C}_{60} \mathrm{~N}$ interlayer can enhance recombination resistance, increase electron extraction rate, and decrease the work function of Ag electrode, which improved the device performance from $7.5 \%$ to $15.5 \%$. The use of a fullerene amine interlayer PCBDAN (Figure 5) was reported to reduce the interface barrier between the $\mathrm{PC}_{61} \mathrm{BM}$ ETL and Ag electrode and also protect device from water corrosion. ${ }^{[87]}$ The device with PCBDAN exhibited a PCE of $17.2 \%$, with an increase of $25 \%$ compared with the device without PCBDAN. Moreover, the device with PCBDAN showed negligible hysteresis. Except for the high PCE, device with PCBDAN also improved the stability of the device due to its hydrophobic property. Recently, a methanolsoluble diamine-modified fullerene derivative PCBDANI (Figure 5) was applied as CBLs in PSCs. ${ }^{[88]}$ The device with PCBDANI single CBL exhibited improved PCE of $15.45 \%$, which 


\section{WILEY-VCH}

was attributed to the formation of an interfacial dipole at the $\mathrm{PC}_{61} \mathrm{BM} / \mathrm{Al}$ interface arising from the amine functional group and the suppression of interfacial recombination by the PCBDANI interlayer. To further improve the device performance, PCBDANI/LiF double CBLs were employed. The device with PCBDANI/LiF double CBLs showed improved PCE of $15.71 \%$ and better stability when compared to the device with LiF single CBL.

All the above-mentioned molecular structures of fullerene CBLs are summarized in Figure 5 and the corresponding photovoltaic parameters are displayed in Table 2. These results clearly demonstrate that polar functional groups of fullerene CBLs play a vital role in forming an interfacial dipole layer to reduce the work function of metal electrode and facilitating ohmic contact between ETL and metal electrode. The decreased work function of the metal electrode is beneficial to facilitate electron transfer from the ETL to the metal electrode by reducing the contact barrier, correlating well with the $V_{\text {ос }}$ gain. The formation of ohmic contact between the ETL and metal electrode can effectively increase the $J_{\text {sc }}$ and FF of devices. For instance, amine functionalized fullerene, crown-ether functionalized fullerene, and fulleropyrrolidine have been extensively utilized as CBLs in PSCs. Among them, amine functionalized fullerenes are the most efficient and widely used CBLs in PSCs because the amine groups can interact with the metal surfaces and form a large negative interfacial dipole between the metal electrode and ETL. However, studies of fullerene CBLs are still limited to a few examples. More investigations are needed to develop novel fullerene CBLs with various function groups, such as carboxylic acid, phosphoric ester, polyethylene glycol, alcohol, or zwitterion etc. Besides the above-mentioned work function tunability and ohmic contact formation, other features of cathode buffer layers including eliminating the hysteresis and protecting perovskite layer from moisture corrosion also need to be further explored.

\section{Figure 5.}




\section{WILEY-VCH}

Table 2.

\section{Fullerene interfacial modification layer for the n-i-p structure}

Apart from the aforementioned electron transport layers and cathode buffer layers for p-i-n PSCs, fullerenes can also be employed as interfacial modification layers and electron transport layers for n-i-p PSCs. To date, $\mathrm{TiO}_{2}$ is the most widely used ETL material for n-i-p PSCs. However, $\mathrm{TiO}_{2}$ based solar cells suffer from reduced stability upon UV exposure and anomalous hysteresis when measured under different scan directions and scan rates. ${ }^{[40,89]}$ To address these issues, various fullerene derivatives have been applied as interfacial modification layers to modify the $\mathrm{TiO}_{2}$ surface. In 2013, Snaith et al. employed a fullerene self-assembled monolayer $\left(\mathrm{C}_{60}\right.$-SAM) to modify the mesoporous $\mathrm{TiO}_{2}$ surface (Figure 6). ${ }^{[90]}$ They found that $\mathrm{C}_{60}-\mathrm{SAM}$ can inhibit electron transfer from the perovskite to $\mathrm{TiO}_{2}$ and reduce $V_{\text {oc }}$ loss. Later on, they reported the surface modification of the $\mathrm{TiO}_{2}$ compact layer with $\mathrm{C}_{60}$-SAM for n-i-p PSCs. ${ }^{[91]}$ The fullerene-modified devices exhibited a PCE of $17.3 \%$ with significantly reduced hysteresis, which was attributed to the passivation effect of $\mathrm{C}_{60}$ SAM that can inhibit the formation of trap states at the perovskite/ $\mathrm{TiO}_{2}$ interfaces.

\section{Figure 6.}

Fullerene $\mathrm{C}_{60}$ and it derivative $\mathrm{PC}_{61} \mathrm{BM}$ are the most widely used interfacial modification layers for n-i-p PSCs. For instance, $\mathrm{C}_{60}$ was used to modified the surface of amorphous $\mathrm{TiO}_{\mathrm{x}}$ layer. ${ }^{[92]}$ The surface energy of $\mathrm{TiO}_{\mathrm{x}}$ films can be tuned by introducing $\mathrm{C}_{60}$ interlayers of varying thicknesses to enhance device performance. The $\mathrm{C}_{60}$ interlayer between $\mathrm{TiO}_{\mathrm{x}}$ and perovskite lowered the injection barrier at the perovskite/ $\mathrm{TiO}_{\mathrm{x}}$ interfaces caused by better energy-level alignment with the $\mathrm{C}_{60}$ contacts. $\mathrm{PC}_{61} \mathrm{BM}$ was employed to modify the lowtemperature solution-processed $\mathrm{TiO}_{\mathrm{x}}$ in n-i-p PSCs. ${ }^{[93]}$ A stabilized PCE of 17.6\% was 


\section{WILEY-VCH}

obtained with negligible hysteresis, due to efficient charge extraction with the modification of $\mathrm{PC}_{61} \mathrm{BM}$. $\mathrm{PC}_{61} \mathrm{BM}$ was also used to modify solution-processed $\mathrm{TiO}_{2}$ to overcome the extremely low electrical conductivity of solution-processed $\mathrm{TiO}_{2}$ ETL in n-i-p PSCs. ${ }^{[94]}$ Due to the much higher electrical conductivity of $\mathrm{PC}_{61} \mathrm{BM}$ than that of $\mathrm{TiO}_{2}$, the charge transfer from the perovskite to the ETL was much more effective, which boosted the device performance. However, the poor wettability of $\mathrm{PbI}_{2}$ on top of $\mathrm{PC}_{61} \mathrm{BM}$ caused insufficient coverage of perovskite film, which is detrimental to device performance. To solve this problem, a water-soluble fullerene derivative WS-C 60 (Figure 7) was deposited on the top of the $\mathrm{PC}_{61} \mathrm{BM}$, leading to a full coverage of the perovskite film and further enhancing the PCE to $14.6 \%$. A successive surface engineering approach was developed for modification of the $\mathrm{TiO}_{2}$ ETL with a hydrophobic $\mathrm{PC}_{61} \mathrm{BM}$ and a hydrophilic ethanolamine-functionalized fullerene $\left(\mathrm{C}_{60}\right.$-ETA, Figure 7) ${ }^{[95]}$ After dual modification of $\mathrm{TiO}_{2}$ with $\mathrm{PC}_{61} \mathrm{BM}$ and $\mathrm{C}_{60}-$ ETA, a maximum PCE of $18.49 \%$ was achieved, which was significantly higher than that of the device based on $\mathrm{TiO}_{2} / \mathrm{PC}_{61} \mathrm{BM}$ or $\mathrm{TiO}_{2} / \mathrm{C}_{60}$-ETA. The synergistic effects of these two fullerene derivatives were revealed: the $\mathrm{PC}_{61} \mathrm{BM}$ layer can passivate the traps on the $\mathrm{TiO}_{2}$ surface, while the hydrophilic $\mathrm{C}_{60}$-ETA layer can improve the wettability of the perovskite film on the ETL and facilitate electron transport from the perovskite to the $\mathrm{TiO}_{2} \mathrm{ETL}$.

In addition to $\mathrm{PC}_{61} \mathrm{BM}, \mathrm{C}_{60}$ derivatives with different functional groups have been developed as interfacial modification layer between the perovskite and $\mathrm{TiO}_{2} \mathrm{ETL}$. A fullerene derivative with a carboxyl group (PCBA, Figure 7) was used as an interfacial modification layer between the perovskite and compact $\mathrm{TiO}_{2}\left(\mathrm{c}-\mathrm{TiO}_{2}\right)$ layer. ${ }^{[96]}$ Compared with $\mathrm{PC}_{61} \mathrm{BM}$, PCBA can form a chemical bond between c- $\mathrm{TiO}_{2}$ and its carboxyl group, most of which cannot be washed away by $N, N$-dimethylformamide (DMF) during the processing of the perovskite layer. PCBA can act as a hole blocking layer, which could passivate the trap sites on the $\mathrm{c}-\mathrm{TiO}_{2}$, reduce the hole recombination at the perovskite/c- $\mathrm{TiO}_{2}$ interfaces and facilitate electron extraction by the ETL. As a result, a PCE of $17.76 \%$ was achieved with a high $V_{\text {oc }}$ of 


\section{WILEY-VCH}

1.16 V. A water-soluble fullerene derivative with hydroxy groups $\left(\mathrm{C}_{60}(\mathrm{OH})_{24-26}\right.$, Figure 7) was employed to modify $\mathrm{TiO}_{2}$ in n-i-p PSCs. ${ }^{[97]}$ The fullerenol was chosen because of its good solubility in water and excellent electron mobility. The insertion of a single layer of fullerenol between the perovskite and $\mathrm{TiO}_{2}$ can dramatically facilitate the charge transportation and decrease the interfacial resistance. As a result, the device PCE was improved from $12.50 \%$ to $14.69 \%$. A triblock fullerene derivative with multifunctional groups (PCBB-2CN-2C8, Figure 7) was synthesized for interface engineering on low temperatureprocessed $\mathrm{TiO}_{2}$ in n-i-p PSCs. ${ }^{[98]}$ Modifying the $\mathrm{TiO}_{2}$ surface with PCBB-2CN-2C8 significantly improved charge extraction from the perovskite layer to the ETL. The $V_{\text {oc }}$ of the device was increased from $0.99 \mathrm{~V}$ to $1.06 \mathrm{~V}$, which was attributed to the uplifted work function of PCBB-2CN-2C8 modified $\mathrm{TiO}_{2}$. The passivation effect of the $\mathrm{TiO}_{2}$ surface by PCBB-2CN-2C8 was responsible for higher current extraction ability, longer lifetime, and better stability in $\mathrm{TiO}_{2} / \mathrm{PCBB}-2 \mathrm{CN}-2 \mathrm{C} 8$ based device.

An additional effect of fullerenes and their derivatives is that they can also act as surface modifiers for other metal oxide materials, such as $\mathrm{WO}_{\mathrm{x}}, \mathrm{ZnO}, \mathrm{In}_{2} \mathrm{O}_{3}, \mathrm{SnO}_{2}, \mathrm{CeO}_{\mathrm{x}}$, etc. For instance, the incorporation of $\mathrm{C}_{60}$ as an interface modifier for $\mathrm{WO}_{\mathrm{x}}$ based PSCs was reported. ${ }^{[99]} \mathrm{WO}_{\mathrm{x}}$ and $\mathrm{C}_{60}$ worked synergistically to further enhance the device performance. $\mathrm{PC}_{61} \mathrm{BM}$ was used to modify the surface of $\mathrm{ZnO}$ for low-temperature-processed n-i-p PSCs. ${ }^{[100]}$ The introduction of $\mathrm{PC}_{61} \mathrm{BM}$ interlayer can smoothen the surface of $\mathrm{ZnO}$, which facilitated the growth of high-quality perovskite absorber layer and resulted in hysteresis-free devices with PCE of 14.5\%. To enhance the performance of $\operatorname{In}_{2} \mathrm{O}_{3}$ based n-i-p PSCs, $\mathrm{PC}_{61} \mathrm{BM}$ was introduced to modify the surface of the $\mathrm{In}_{2} \mathrm{O}_{3}$ ETL. ${ }^{[101]} \mathrm{PC}_{61} \mathrm{BM}$ film can fill up the pinholes or cracks along $\operatorname{In}_{2} \mathrm{O}_{3}$ grain boundaries to passivate the defects and smoothen the surface of ETLs. $\mathrm{PC}_{61} \mathrm{BM}$ was also used to passivate the surface of $\mathrm{SnO}_{2} \cdot{ }^{[102]}$ The $\mathrm{SnO}_{2} \mathrm{ETL}$ can block holes effectively, while the $\mathrm{PC}_{61} \mathrm{BM}$ can promote electron transfer and passivate both the $\mathrm{SnO}_{2}$ /perovskite interface and perovskite grain boundaries. The device using 


\section{WILEY-VCH}

PC ${ }_{61} \mathrm{BM}$-passivated $\mathrm{SnO}_{2}$ ETLs achieved a PCE of $19.12 \%$, which was attributed to the improved electron transfer and reduced charge recombination at the ETL/perovskite interfaces. $\mathrm{PC}_{61} \mathrm{BM}$ was used as interfacial modification layer between the $\mathrm{CeO}_{\mathrm{x}} \mathrm{ETL}$ and perovskite layer for efficient and stable n-i-p PSCs. ${ }^{[103]}$ The PCE of $\mathrm{CeO}_{\mathrm{x}}$ based device was increased from $14.32 \%$ to $17.04 \%$ by the introduction of a thin layer of $\mathrm{PC}_{61} \mathrm{BM}$ between the $\mathrm{CeO}_{\mathrm{x}}$ ETL and perovskite.

Recently, a systematical investigation about the influence of different fullerene interface modifiers on the performance and hysteresis of n-i-p PSCs was demonstrated. ${ }^{[104]}$ The device performance of PSCs with a variety of ETLs including $\mathrm{TiO}_{2}, \mathrm{SnO}_{2}, \mathrm{C}_{60}, \mathrm{PC}_{61} \mathrm{BM}$, ICMA (Figure 7), $\mathrm{TiO}_{2} / \mathrm{PC}_{61} \mathrm{BM}$, and $\mathrm{SnO}_{2} / \mathrm{PC}_{61} \mathrm{BM}$ were analyzed. It was demonstrated that only double-layer ETL $\left(\mathrm{TiO}_{2} / \mathrm{PC}_{61} \mathrm{BM}\right)$ structures can substantially eliminate the hysteresis effects and significantly enhance the PCE to $18.0 \%$, which benefited from improved hole blocking by the wide band gap metal oxide and decreased transport losses by fullerene modification.

The molecular structures of fullerene interfacial modification layers are summarized in Figure 7 and the corresponding photovoltaic parameters are presented in Table 3. The abovementioned analyses clearly demonstrate that the metal oxide ETL and fullerene interface modifier work cooperatively to boost the performance of PSCs. Fullerenes and their derivatives are excellent passivation materials for perovskite, which can effectively passivate the grain boundaries in the perovskite and reduce the density of trap states as well as reduce hysteresis of PSCs. However, they cannot block holes as efficiently as metal oxide ETL because of their relatively smaller bandgaps. The use of metal oxide/fullerene double ETLs can combine the benefits of both materials, i.e., the metal oxide effectively blocks holes and the fullerene modifier greatly promote electron transfer and passivate the perovskite. Thus, the interaction between the metal oxide ETL and fullerene modifier is crucial to eliminate hysteresis and improve device performance in n-i-p PSCs. Since the interaction is mainly from the functional groups of fullerene that can be anchored onto the metal oxide surfaces, the 


\section{WILEY-VCH}

chemical structure of fullerene modifier can significantly affect the performance. For instance, $\mathrm{PC}_{61} \mathrm{BM}$ is a better interface modifier than $\mathrm{C}_{60}$ because the carboxylate group of $\mathrm{PC}_{61} \mathrm{BM}$ can be anchored on the metal oxide surfaces. Although $\mathrm{PC}_{61} \mathrm{BM}$ is the most widely used interfacial modification layer in n-i-p PSCs, the relatively weak interaction between $\mathrm{PC}_{61} \mathrm{BM}$ and the metal oxide surface makes it easy to wash away most $\mathrm{PC}_{61} \mathrm{BM}$ during the spincoating process of perovskite precursor. Fullerene modifier with various anchoring groups that are covalently anchored onto the metal oxide surfaces including carboxyl group, hydroxyl group, amine group etc., is expected to be better interface modifier than $\mathrm{PC}_{61} \mathrm{BM}$. Therefore, fullerene and their derivatives with anchoring groups are ideal materials for interface modification because of their relatively high conductivity, high electron mobility, suitable energy levels and good passivation effect.

Figure 7.

Table 3.

\section{Fullerene electron transport layer for the n-i-p structure}

For n-i-p PSCs, a variety of inorganic n-type materials including $\mathrm{TiO}_{2}, \mathrm{ZnO}^{[105]} \mathrm{SnO}_{2},{ }^{[106]}$ $\mathrm{WO}_{\mathbf{x}}{ }^{[107]} \mathrm{In}_{2} \mathrm{O}_{3},{ }^{[101]} \mathrm{Nb}_{2} \mathrm{O}_{5},{ }^{[108]} \mathrm{CeO}_{x},{ }^{[103]} \mathrm{Fe}_{2} \mathrm{O}_{3},{ }^{[109]} \mathrm{Zn}_{2} \mathrm{SnO}_{4},{ }^{[110]}$ aluminum-doped zinc oxide (AZO) $,{ }^{[111]} \mathrm{SrTiO}_{3},{ }^{[112]} \mathrm{BaSnO}_{3},{ }^{[113]} \mathrm{CdS},{ }^{[114]} \mathrm{ZnS},{ }^{[114]} \mathrm{CdSe}^{[115]}$ etc. have been successfully employed as the ETL due to their well-matched energy levels with perovskites, high electron mobility, and high transparency in the visible region. Among these, $\mathrm{TiO}_{2}$ is the most commonly used ETL in high performance PSCs. Despite the high performance of $\mathrm{TiO}_{2}$ based PSCs, the $\mathrm{TiO}_{2}$ ETL usually requires a high-temperature $\left(>450^{\circ} \mathrm{C}\right)$ sintering process to obtain highly crystallized $\mathrm{TiO}_{2}$ film, which is incompatible with flexible plastic substrates. Although low-temperature processed $\left(<150{ }^{\circ} \mathrm{C}\right) \mathrm{TiO}_{2},{ }^{[116]} \mathrm{ZnO}^{[105]} \mathrm{Zn}_{2} \mathrm{SnO}_{4},{ }^{[110]}$ or $\mathrm{CdSe}^{[115]}$ 


\section{WILEY-VCH}

nanoparticles have been developed to solve this limitation, the complicated fabrication processes and difficulty in precise size control hinder their practical applications for mass production. Besides, devices based on these low-temperature processed ETLs still suffer from a large hysteresis. All these challenges need to be addressed before their commercialization. Compared to the inorganic ETLs, fullerene based organic ETLs are promising alternatives to their inorganic counterparts because of their advantages, such as low-temperature processing, compatibility with flexible substrates, and hysteresis suppression. For instance, Snaith et al. used solution-processed $\mathrm{C}_{60}$ to replace the commonly used $\mathrm{TiO}_{2}$ as ETL in regular n-i-p PSCs. ${ }^{[117]}$ They demonstrated that replacing $\mathrm{TiO}_{2}$ with $\mathrm{C}_{60}$ can improve charge extraction, alleviate hysteresis effect, and achieve high stabilized PCE. Vacuum-processed $\mathrm{C}_{60}$ was also employed as ETL in n-i-p PSCs. ${ }^{[118]}$ By optimizing the thickness of the vacuumprocessed $\mathrm{C}_{60}$ ETL, hysteresis-free low-temperature-processed n-i-p PSCs were fabricated with PCE of $19.1 \%{ }^{[119]}$ Moreover, hysteresis-free flexible PSCs were also fabricated using the $\mathrm{C}_{60}$ ETL on polyethylene naphthalate (PEN) substrates with PCE of $16.0 \%$. Besides $\mathrm{C}_{60}$, the use of vacuum-deposited $\mathrm{C}_{70}$ as ETL in n-i-p PSCs was reported. ${ }^{[120]} \mathrm{A}$ comparative and systematic investigation of solution-processed $\mathrm{C}_{60}$ and $\mathrm{C}_{70}$ as ETL in n-i-p PSCs was also demonstrated. ${ }^{[121]} \mathrm{C}_{60}$ and $\mathrm{C}_{70}$ have similar LUMO energy levels. However, $\mathrm{C}_{70}$ exhibits much lower electron mobility and shows higher absorption in the visible region. Devices based on $\mathrm{C}_{60}$ and $\mathrm{C}_{70}$ showed comparable PCE (10\%). $\mathrm{C}_{70}$ based device displayed slightly higher $V_{\mathrm{oc}}$, but lower $\mathrm{J}_{\mathrm{sc}}$ compared to $\mathrm{C}_{60}$ based device. The photocurrent decrease in $\mathrm{C}_{70}$ based device was attributed to the higher sunlight absorption in the $\mathrm{C}_{70}$ film which may disturb the light-harvesting of perovskite. Due to relatively low electron mobility of $\mathrm{C}_{70}$, the device efficiencies of $\mathrm{C}_{70}$ based devices were much more sensitive to the thickness of fullerene film than those of $\mathrm{C}_{60}$ based devices.

In addition to pristine fullerenes, fullerene derivatives have been effectively utilized as ETLs in n-i-p PSCs. PSCs employing PC ${ }_{61}$ BM ETL exhibited a PCE of $15.3 \%$ with obvious 


\section{WILEY-VCH}

hysteresis. ${ }^{[122]}$ To further reduce the hysteresis of $\mathrm{PC}_{61} \mathrm{BM}$ based device, bilayered ETLs that is composed of fulleropyrrolidinium iodide (FPI)-polyethyleneimine (PEIE) and $\mathrm{PC}_{61} \mathrm{BM}$ were adopted. ${ }^{[123]} \mathrm{PC}_{61} \mathrm{BM}$ can facilitate the crystallization of perovskite and promote charge extraction at the perovskite/ETL interfaces. FPI-PEIE can tune the work function of indium tin oxide (ITO) and dope the $\mathrm{PC}_{61} \mathrm{BM}$ to achieve high conductivity for efficient electron transport. As a result, devices based on bilayered ETL exhibited a PCE of 15.7\% with insignificant hysteresis. In a similar way, low-temperature-processed, hysteresis-free, and stable PSCs using PEIE doped $\mathrm{PC}_{61} \mathrm{BM}$ as ETLs were also reported. ${ }^{[124]}$ The PEIE: PC ${ }_{61} \mathrm{BM}$ film combines the work function tunability of polyelectrolyte and the electron accepting property of fullerene derivative. Hysteresis-free PSCs with stabilized PCE of 18.1\% were achieved by using the self-organized PEIE: PC ${ }_{61}$ BM ETL. A self-organized PCBDAN interlayer was introduced into the $\mathrm{PC}_{61} \mathrm{BM}$ ETL to form $\mathrm{PC}_{61} \mathrm{BM}$ : PCBDAN layers to improve the performance of n-i-p PSCs. ${ }^{[125]}$ PCBDAN can reduce the work function of ITO and eliminate the interface barrier between the ETL and electrode. By employing the PC 61 BM: PCBDAN ETL, a high PCE of $18.1 \%$ was obtained with negligible hysteresis. A carboxyl-functionalized fullerene derivative CPTA (Figure 8) was employed to replace metal oxide as the ETL for high efficient, hysteresis-free, and stable PSCs. ${ }^{[126]}$ The CPTA film was covalently anchored onto the ITO surface, significantly suppressing hysteresis and improving flexural strength. The best device on the ITO glass substrate exhibited a high PCE of 18.39\% and excellent long-term stability over 100 days without encapsulation. The flexible device on ITO/poly(ethylene terephthalate) (PET) substrate showed a promising PCE of 17.04\% and remarkable durability against mechanical bending over 1000 times.

Although $\mathrm{PC}_{61} \mathrm{BM}$ is an excellent ETL for n-i-p PSCs, it can be dissolved and washed away from the substrate by DMF during perovskite deposition. ${ }^{[102,122]}$ To address this issue, PC 61 BM was crosslinked with 1,6-diazidohexane (DAZH) to increase its solvent resistance. ${ }^{[127]}$ The crosslinked $\mathrm{PC}_{61} \mathrm{BM}$ layer was resistant against solvent like DMF, and can 


\section{WILEY-VCH}

be used as ETLs or surface modification layers for n-i-p PSCs. Device with crosslinked $\mathrm{PC}_{61} \mathrm{BM}$ ETL exhibited PCE of 14.9\%, slightly higher than that of the device with pristine $\mathrm{PC}_{61} \mathrm{BM}$ (11.9\%). To further improve the device performance, an addition hole blocking layer $\left(\mathrm{TiO}_{2}\right.$ or PEIE) was deposited between ITO and the crosslinked $\mathrm{PC}_{61} \mathrm{BM}$ layer due to the relatively poor hole blocking ability of $\mathrm{PC}_{61} \mathrm{BM}$. A maximum PCE of $18.4 \%$ was achieved with the $\mathrm{TiO}_{2} /$ crosslinked $\mathrm{PC}_{61} \mathrm{BM}$ ETL. Snaith et al. reported the use of cross-linkable fullerene derivatives as the ETL in n-i-p PSCs to obtain insolubilized fullerene ETLs. ${ }^{[128]}$ Two approaches were developed to form insolubilized fullerene films. One approach was based on sol-gel $\mathrm{C}_{60}$ (Figure 8) which was cross-linked by exposure to trifluoroacetic acid vapor to generate insoluble sol-gel film. Another approach involved ring-opening reaction of a fullerene derivative phenyl- $\mathrm{C}_{61}$-butyric acid benzocyclobutene ester (PCBCB, Figure 8), which was crossed-linked by thermal annealing at $200{ }^{\circ} \mathrm{C}$. A PCE of $17.9 \%$ was achieved for devices based on both of the two cross-linked fullerenes, which was higher than that of reference device using solution-processed $\mathrm{C}_{60}(14.7 \%)$. Compared to devices employing $\mathrm{C}_{60}$, devices using the two cross-linked fullerenes exhibited higher $V_{\mathrm{oc}}$ and $J_{\mathrm{sc}}$, which could be related to the reduced shunting paths and improved hole-blocking properties. Recently, a novel styrene-functionalized fullerene derivative MPMIC $_{60}$ (Figure 8) was developed to replace the fragile $\mathrm{C}_{60}$ and $\mathrm{PC}_{61}$ BM ETLs in both n-i-p and p-i-n PSCs. ${ }^{[129]}$ MPMIC $_{60}$ can be cross-linked and transformed into a solvent-resistant film through curing at $250{ }^{\circ} \mathrm{C}$. Regular device using cured-MPMIC 60 exhibited a PCE of $13.8 \%$, which was only slightly lower than that of $\mathrm{C}_{60}$ control device (14.8\%). Compared to cured MPMIC $_{60}$ cells, uncured MPMIC 60 cells showed lower $V_{\text {oc }}$, resulting from formation of shunts by solvent etching during perovskite deposition.

All the above-mentioned molecular structures of fullerene ETLs for n-i-p PSCs are summarized in Figure 8 and the corresponding photovoltaic parameters are shown in Table 4 . The requirements for efficient ETLs in n-i-p PSCs are analogous to those of ETLs in p-i-n 


\section{WILEY-VCH}

PSCs, such as energy matching between perovskite and fullerene ETL, and high electron mobility. However, different to the p-i-n PSCs, perovskite layer is deposited on top of the fullerene ETL in n-i-p PSCs. Therefore, the surface wettability of fullerene ETL can affect the growth of perovskite layer and the resulting device performance. In addition, the interaction between the underneath ITO or FTO substrate and fullerene ETL also needs to be considered. Therefore, fullerene ETLs that can be anchored on ITO or FTO substrate and have suitable surface wettability for perovskite deposition is highly desirable for high performance n-i-p PSCs. For instance, CPTA outperforms $\mathrm{PC}_{61} \mathrm{BM}$ because of better interfacial contact between CPTA and the ITO surface as well as improved surface coverage of perovskite films on the CPTA/ITO substrate.

Compared to a large variety of fullerene ETLs for p-i-n PSCs, the number of fullerene ETLs for n-i-p PSCs is still very limited. The incorporation of fullerene derivatives into n-i-p PSCs is limited by the lack of orthogonal solvent systems for device fabrication because most of the fullerene derivatives can be dissolved and washed away by DMF or DMSO. Nevertheless, fullerene ETLs have been regarded as promising alternatives to replace the commonly used $\mathrm{TiO}_{2}$ in regular n-i-p PSCs, in particular for flexible PSCs, because they can be fabricated through low-temperature solution process and have perfect compatibility with flexible substrates. Therefore, it is desirable to develop rationally designed fullerene ETLs with solvent-resistant for realizing efficient and robust flexible PSCs.

\section{Figure 8.}

Table 4.

\section{Perovskite-fullerene heterojunction}




\section{WILEY-VCH}

Recent studies show that the presence of unbalanced electron and hole diffusion length is a ubiquitous feature of lead halide perovskite. ${ }^{[11,130-133]}$ Holes are extracted more efficiently than electrons in perovskites, because the diffusion length of electrons is shorter than that of holes. Therefore, promoting the electron extraction efficiency and making it comparable with hole extraction efficiency is critical for further improvement in device performance. The incorporation of fullerenes and their derivatives in perovskite has been proven to promote the electron extraction efficiency and thus further improve the device performance.

$\mathrm{PC}_{61} \mathrm{BM}$ has been extensively investigated in perovskite- $\mathrm{PC}_{61} \mathrm{BM}$ bulk heterojunction to enhance device efficiency and reduce hysteresis. For instance, Sargent et al. reported the use of perovskite-PC ${ }_{61} \mathrm{BM}$ bulk heterojunction in n-i-p PSCs to reduce hysteresis and improve device performance. ${ }^{[134]}$ The homogeneously distributed $\mathrm{PC}_{61} \mathrm{BM}$ can passivate iodide-rich trap sites on the surfaces of perovskite grains and promote electron extraction, leading to suppressed hysteresis and enhanced photovoltage. The perovskite-PC ${ }_{61} \mathrm{BM}$ bulk heterojunction concept was also adopted to fabricate p-i-n PSCs with a high FF of 0.82 and no hysteresis. ${ }^{[135]}$ The excellent performance of perovskite-fullerene bulk heterojunction device was contributed to high conductivity and balanced electron and hole extraction of the perovskite-PC ${ }_{61} \mathrm{BM}$ film. Recent studies revealed that the incorporation of $\mathrm{PC}_{61} \mathrm{BM}$ in perovskite can suppress the drift of ions and promote charge extraction efficiency, which suppress hysteresis and improve device performance. ${ }^{[136,137]}$ One dimensional PC 61 BM nanorods were added into the perovskite to form a wrinkle-like bicontinuous perovskite layer. ${ }^{[138]}$ The interconnected one dimensional $\mathrm{PC}_{61} \mathrm{BM}\left(1 \mathrm{D} \mathrm{PC}_{61} \mathrm{BM}\right)$ nanorods within the perovskite material can efficiently facilitate the photogenerated charge separation and carrier transportation process. A PCE of $15.3 \%$ with improved device working stability was obtained by optimizing one dimensional $\mathrm{PC}_{61} \mathrm{BM}$ nanorod content. Recently, mesostructured n-i-p PSCs were fabricated on a novel mesostructured PC 61 BM (ms-PC 61 BM) ETL. ${ }^{[139]}$ The msPC ${ }_{61} \mathrm{BM}$ promoted the growth of larger perovskite domains and reduced trap state density in 


\section{WILEY-VCH}

the perovskite film grown atop. These benefits improved the device efficiency up to $15 \%$ and reduced hysteresis.

To control the formation of a gradient distribution of $\mathrm{PC}_{61} \mathrm{BM}$ in the perovskite layer to further enhance the performance of p-i-n PSCs, a novel perovskite-fullerene graded heterojunction (GHJ, Figure 9) was developed. ${ }^{[140]}$ Compared to planar heterojunction and bulk heterojunction, graded heterojunction structure was beneficial to interfacial charge collection because it assists the electrons and holes flowing to the opposite side. As a result, the graded heterojunction structure significantly improved the electron collection and greatly reduced recombination loss, resulting in high device efficiency with small hysteresis and good stability. By employing this strategy, a certified PCE of $18.21 \%$ with area over $1 \mathrm{~cm}^{2}$ was obtained.

\section{Figure 9.}

In addition to $\mathrm{PC}_{61} \mathrm{BM}$, other $\mathrm{C}_{60}$ derivatives as well as pristine fullerene $\left(\mathrm{C}_{60}\right.$ and $\left.\mathrm{C}_{70}\right)$ are also incorporated into the perovskite to form perovskite-fullerene bulk heterojunctions. A variety of $\mathrm{C}_{60}$ derivatives including pyrazolino[60]fullerene derivatives (PI-1 and PI-2), isoxazolino[60]fullerene derivatives (IS-1 and IS-2), and methano[60]fullerene derivatives (DPM-6 and PC ${ }_{61} \mathrm{BM}$ ) (Figure 10) were used to fabricated electron transport layer-free PSCs based on perovskite-fullerene heterojunction. ${ }^{[141]}$ A PCE of $14.3 \%$ was obtained for device based on perovskite-IS2 heterojunction. The device $V_{\text {oc }}$ increases with the elevated LUMO energy levels of the fullerene component. To balance the charge extraction efficiencies, Gong et al. fabricated perovskite-fullerene bulk heterojunction PSCs by mixing perovskitse with water-/alcohol-soluble fullerene derivative $\mathrm{A}_{10} \mathrm{C}_{60}$ (also called WS- $\mathrm{C}_{60}$ ). ${ }^{[142]} \mathrm{A}$ remarkable FF of $86.7 \%$ was obtained for the perovskite-fullerene bulk heterojunction device, originating from the balanced charge carrier extraction efficiency and enlarged interfacial area between 


\section{WILEY-VCH}

the perovskite and $\mathrm{A}_{10} \mathrm{C}_{60}$. Pristine fullerene $\mathrm{C}_{60}$ was introduced in hybrid $\mathrm{MAPb}_{0.75} \mathrm{Sn}_{0.25} \mathrm{I}_{3}$ perovskite to form the perovskite- $\mathrm{C}_{60}$ heterojunction, which increased the bulk and surface recombination lifetimes and decreased the charge trap-state density. ${ }^{[143]}$ As a result, the perovskite-C 60 hybrid solar cells demonstrated PCE of 13.9\% with less hysteresis and higher long-term stability. Electron transport layer-free PSCs were also fabricated based on perovskite- $C_{70}$ heterojunction films. ${ }^{[144]}$ A PCE of $13.6 \%$ was achieved for these devices. Compared with conventional compact $\mathrm{TiO}_{2}$ based device, the unencapsulated perovskite- $\mathrm{C}_{70}$ device exhibited enhanced photostability.

In order to simultaneously improve the device performance and stability, hydrophobic fullerene derivatives have been developed in perovskite-fullerene bulk heterojunction devices. For instance, isomer-pure bis-PCBM ( $\alpha$-bis-PCBM, Figure 10) was employed as a templating agent for the perovskite film. ${ }^{[145]}$. The introduction of $\alpha$-bis-PCBM into the perovskite enhanced the crystallization of the perovskite film, improved electron extraction, and improved the stability of PSCs, because $\alpha$-bis-PCBM can passivate the voids or pinholes generated in the active layer and prevent the erosion of perovskites by moisture. A PCE of $20.8 \%$ was obtained for $\alpha$-bis-PCBM-containing PSCs, compared with $19.9 \%$ of $\mathrm{PC}_{61} \mathrm{BM}$ containing PSCs. More importantly, the $\alpha$-bis-PCBM-containing PSCs exhibited excellent stability under heat and simulated sunlight. A cross-linkable fullerene derivative PCBSD (Figure 10) was introduced into the perovskite to improve device performance and stability. ${ }^{[146]}$ The cross-linked PCBSD (C-PCBSD) can enhance the crystallization of the perovskite and address the issue of low electron extraction efficiency. The solvent-resistant network of C-PCBSD facilitated the sequential solution process because it cannot be washed away by the solvent used in the upper layer. Moreover, the C-PCBSD network can resist moisture incursion, thus preventing erosion of the interfaces and passivating the voids or pinholes in the perovskite layer. Recently, Jen et al. reported the use of perovskite-fullerene heterojunction with a fluoroalkyl-substituted fullerene (DF-C60, Figure 10) for efficient and 


\section{WILEY-VCH}

ambient stable PSCs. ${ }^{[147]}$ DF-C $_{60}$ can effectively passivate the defects and grain boundaries in the perovskite film to facilitate charge transport/collection. As a result, an enhanced PCE of $18.11 \%$ with small hysteresis was achieved, which might be due to the preferential distribution of low surface energy DF-C 60 nearby the surface region of the perovskite fullerene film. More importantly, the perovskite-fullerene device showed excellent ambient stability without encapsulation, which was attributed to the hydrophobic nature of DF-C 60 .

The molecular structures of fullerenes and their derivatives incorporated into perovskitefullerene heterojunctions are summarized in Figure 10 and the corresponding photovoltaic parameters are shown in Table 5. These results clearly demonstrated that the chemical modifications on the fullerenes are beneficial for their use in perovskite-fullerene heterojunction for photovoltaic applications. For instance, $\mathrm{C}_{60}$ derivative $\mathrm{PC}_{61} \mathrm{BM}$ performed better than pristine fullerene, such as $\mathrm{C}_{60}$ and $\mathrm{C}_{70}$. Besides, studies revealed that there was a correlation between the $V_{\text {ос }}$ of perovskite-fullerene heterojunction solar cells and the LUMO energy level of the fullerene material, which can be tuned by chemical modification of fullerenes. Compared with perovskite-fullerene heterojunction solar cells based on $\mathrm{PC}_{61} \mathrm{BM}$, devices based on hydrophobic fullerene derivative such as $\alpha$-bis-PCBM or DF-C60 exhibited superior stability. However, the number of fullerene material that can be used in perovskitefullerene heterojunction solar cells is still limited. Therefore, increasing efforts are needed to develop novel fullerene derivatives for high-performance, hysteresis-free, and stable perovskite-fullerene heterojunction solar cells.

\section{Figure 10.}

Table 5.

\section{Conclusion}




\section{WILEY-VCH}

In summary, this review demonstrates the versatility of fullerene-based materials in PSCs.

The use of fullerenes and their derivatives as electron transport layers, interfacial modification layers, and trap state passivators to improve device efficiency, eliminate hysteresis, and enhance device stability of PSCs has brought significant advances in this field since the last few years. Importantly, the beneficial effects obtained by the use of fullerenes are closely related to their chemical structures as well as their self-aggregations, allowing the fine tuning of their properties by chemical modifications. Improving efficiency and long-term stability of PSCs is crucial for their practical applications. These issues are anticipated to be addressed by incorporating hydrophobic, cross-linked, and doped fullerene materials. Moreover, the lowtemperature solution-processed fullerenes offer the potential for fabricating large-area, flexible devices with low cost. Thus, developing novel fullerenes with specific features including excellent moisture and solvent resistance, high conductivity etc., will further promote the development of PSCs towards high efficiency, negligible hysteresis, and high stability.

\section{Acknowledgements}

This work was supported by the 973 Project (2014CB845601), the National Science Foundation of China (U1205111, 21390390, 21721001, and 51502252), the Swedish Research Councils (VR, Grant No. 330-2014-6433 and FORMAS, Grant No. 942-2015-1253), the European Commission Marie Skłodowska- Curie Actions (Grant No. INCA 600398), the Swedish Government Strategic Research Area in Materials Science on Functional Materials at Linköping University (Faculty Grant SFO-Mat-LiU \# 2009-00971). L. L. Deng acknowledges the China Scholarship Council (No. 201706315013) for the financial support.

Received: ((will be filled in by the editorial staff))

Revised: ((will be filled in by the editorial staff)) Published online: ((will be filled in by the editorial staff)) 


\section{WILEY-VCH}

\section{References}

[1] M. A. Green, A. Ho-Baillie, H. J. Snaith, Nat. Photonics 2014, 8, 506.

[2] N.-G. Park, J. Phys. Chem. Lett. 2013, 4, 2423.

[3] H. J. Snaith, J. Phys. Chem. Lett. 2013, 4, 3623.

[4] P. Gao, M. Grätzel, M. K. Nazeeruddin, Energy Environ. Sci. 2014, 7, 2448.

[5] Q. Lin, A. Armin, P. L. Burn, P. Meredith, Acc. Chem. Res. 2016, 49, 545.

[6] B. Saparov, D. B. Mitzi, Chem. Rev. 2016, 116, 4558.

[7] H.-S. Kim, S. H. Im, N.-G. Park, J. Phys. Chem. C 2014, 118, 5615.

[8] C. C. Stoumpos, C. D. Malliakas, M. G. Kanatzidis, Inorg. Chem. 2013, 52, 9019.

[9] C. Wehrenfennig, G. E. Eperon, M. B. Johnston, H. J. Snaith, L. M. Herz, Adv. Mater. 2014, 26, 1584.

[10] S. D. Stranks, G. E. Eperon, G. Grancini, C. Menelaou, M. J. P. Alcocer, T. Leijtens, L. M. Herz, A. Petrozza, H. J. Snaith, Science 2013, 342, 341.

[11] G. Xing, N. Mathews, S. Sun, S. S. Lim, Y. M. Lam, M. Grätzel, S. Mhaisalkar, T. C. Sum, Science 2013, 342, 344.

[12] Q. Dong, Y. Fang, Y. Shao, P. Mulligan, J. Qiu, L. Cao, J. Huang, Science 2015, 347, 967.

[13] A. Kojima, K. Teshima, Y. Shirai, T. Miyasaka, J. Am. Chem. Soc. 2009, 131, 6050.

[14] H.-S. Kim, C.-R. Lee, J.-H. Im, K.-B. Lee, T. Moehl, A. Marchioro, S.-J. Moon, R. Humphry-Baker, J.-H. Yum, J. E. Moser, M. Grätzel, N.-G. Park, Sci. Rep. 2012, 2, 591.

[15] M. M. Lee, J. Teuscher, T. Miyasaka, T. N. Murakami, H. J. Snaith, Science 2012, 338, 643.

[16] J. Burschka, N. Pellet, S.-J. Moon, R. Humphry-Baker, P. Gao, M. K. Nazeeruddin, M. Grätzel, Nature 2013, 499, 316.

[17] H. Zhou, Q. Chen, G. Li, S. Luo, T.-b. Song, H.-S. Duan, Z. Hong, J. You, Y. Liu, Y. Yang, Science 2014, 345, 542. 


\section{WILEY-VCH}

[18] W. S. Yang, J. H. Noh, N. J. Jeon, Y. C. Kim, S. Ryu, J. Seo, S. I. Seok, Science 2015, 348, 1234.

[19] W. Chen, Y. Wu, Y. Yue, J. Liu, W. Zhang, X. Yang, H. Chen, E. Bi, I. Ashraful, M. Grätzel, L. Han, Science 2015, 350, 944.

[20] M. Saliba, T. Matsui, J.-Y. Seo, K. Domanski, J.-P. Correa-Baena, M. K. Nazeeruddin,

S. M. Zakeeruddin, W. Tress, A. Abate, A. Hagfeldt, M. Grätzel, Energy Environ. Sci. 2016, 9, 1989.

[21] W. S. Yang, B.-W. Park, E. H. Jung, N. J. Jeon, Y. C. Kim, D. U. Lee, S. S. Shin, J. Seo, E. K. Kim, J. H. Noh, S. I. Seok, Science 2017, 356, 1376.

[22] M. Grätzel, Nat. Mater. 2014, 13, 838.

[23] H. J. Snaith, A. Abate, J. M. Ball, G. E. Eperon, T. Leijtens, N. K. Noel, S. D. Stranks, J. T.-W. Wang, K. Wojciechowski, W. Zhang, J. Phys. Chem. Lett. 2014, 5, 1511.

[24] A. Babayigit, A. Ethirajan, M. Muller, B. Conings, Nat. Mater. 2016, 15, 247.

[25] T. A. Berhe, W.-N. Su, C.-H. Chen, C.-J. Pan, J.-H. Cheng, H.-M. Chen, M.-C. Tsai, L.-Y. Chen, A. A. Dubale, B.-J. Hwang, Energy Environ. Sci. 2016, 9, 323.

[26] S. T. Williams, A. Rajagopal, C.-C. Chueh, A. K. Y. Jen, J. Phys. Chem. Lett. 2016, 7, 811.

[27] F. Giustino, H. J. Snaith, ACS Energy Lett. 2016, 1, 1233.

[28] Z. Shi, J. Guo, Y. Chen, Q. Li, Y. Pan, H. Zhang, Y. Xia, W. Huang, Adv. Mater. 2017, 29, 1605005.

[29] M. Lyu, J.-H. Yun, P. Chen, M. Hao, L. Wang, Adv. Energy Mater. 2017, 7, 1602512.

[30] G. Niu, X. Guo, L. Wang, J. Mater. Chem. A 2015, 3, 8970.

[31] N. H. Tiep, Z. Ku, H. J. Fan, Adv. Energy Mater. 2016, 6, 1501420.

[32] B. Li, Y. Li, C. Zheng, D. Gao, W. Huang, RSC Adv. 2016, 6, 38079.

[33] Y. Chen, T. Chen, L. Dai, Adv. Mater. 2015, 27, 1053.

[34] J. Xu, Y. Chen, L. Dai, Nat. Commun. 2015, 6, 8103. 


\section{WILEY-VCH}

[35] Z. Wang, Z. Shi, T. Li, Y. Chen, W. Huang, Angew. Chem., Int. Ed. 2016, 56, 1190.

[36] T. M. Koh, K. Thirumal, H. S. Soo, N. Mathews, ChemSusChem 2016, 9, 2541.

[37] R. K Misra, B.-E. Cohen, L. Iagher, L. Etgar, ChemSusChem 2017, DOI:

\subsection{2/cssc.201701026.}

[38] T. Li, Y. Pan, Z. Wang, Y. Xia, Y. Chen, W. Huang, J. Mater. Chem. A 2017, 5, 12602.

[39] J. Chen, X. Cai, D. Yang, D. Song, J. Wang, J. Jiang, A. Ma, S. Lv, M. Z. Hu, C. Ni, J. Power Sources 2017, 355, 98.

[40] B. Chen, M. Yang, S. Priya, K. Zhu, J. Phys. Chem. Lett. 2016, 7, 905.

[41] S. van Reenen, M. Kemerink, H. J. Snaith, J. Phys. Chem. Lett. 2015, 6, 3808.

[42] H. W. Kroto, J. R. Heath, S. C. O'Brien, R. F. Curl, R. E. Smalley, Nature 1985, 318, 162.

[43] C. A. Reed, R. D. Bolskar, Chem. Rev. 2000, 100, 1075.

[44] D. M. Guldi, P. Neta, K.-D. Asmus, J. Phys. Chem. 1994, 98, 4617.

[45] H. Imahori, K. Hagiwara, T. Akiyama, M. Aoki, S. Taniguchi, T. Okada, M.

Shirakawa, Y. Sakata, Chem. Phys. Lett. 1996, 263, 545.

[46] H. Imahori, Y. Sakata, Adv. Mater. 1997, 9, 537.

[47] E. Frankevich, Y. Maruyama, H. Ogata, Chem. Phys. Lett. 1993, 214, 39.

[48] C. P. Jarrett, K. Pichler, R. Newbould, R. H. Friend, Synth. Met. 1996, 77, 35.

[49] O. A. Gudaev, V. K. Malinovsky, A. V. Okotrub, Y. V. Shevtsov, Fullerene Sci.

Technol. 1998, 6, 433.

[50] C.-Z. Li, C.-C. Chueh, H.-L. Yip, J. Zou, W.-C. Chen, A. K. Y. Jen, J. Mater. Chem. 2012, 22, 14976.

[51] L. Meng, J. You, T.-F. Guo, Y. Yang, Acc. Chem. Res. 2016, 49, 155.

[52] C. Cui, Y. Li, Y. Li, Adv. Energy Mater. 2017, 7, 1601251.

[53] Y. Fang, C. Bi, D. Wang, J. Huang, ACS Energy Lett. 2017, 2, 782. 


\section{WILEY-VCH}

[54] J.-Y. Jeng, Y.-F. Chiang, M.-H. Lee, S.-R. Peng, T.-F. Guo, P. Chen, T.-C. Wen, Adv. Mater. 2013, 25, 3727.

[55] S. Sun, T. Salim, N. Mathews, M. Duchamp, C. Boothroyd, G. Xing, T. C. Sum, Y. M. Lam, Energy Environ. Sci. 2014, 7, 399.

[56] C.-H. Chiang, Z.-L. Tseng, C.-G. Wu, J. Mater. Chem. A 2014, 2, 15897.

[57] S.-M. Dai, X. Zhang, W.-Y. Chen, X. Li, Z. a. Tan, C. Li, L.-L. Deng, X.-X. Zhan, M.-S. Lin, Z. Xing, T. Wen, R.-M. Ho, S.-Y. Xie, R.-B. Huang, L.-S. Zheng, J. Mater. Chem. A 2016, 4, 18776.

[58] W. Nie, H. Tsai, R. Asadpour, J.-C. Blancon, A. J. Neukirch, G. Gupta, J. J. Crochet, M. Chhowalla, S. Tretiak, M. A. Alam, H.-L. Wang, A. D. Mohite, Science 2015, 347, 522.

[59] C. Bi, Q. Wang, Y. Shao, Y. Yuan, Z. Xiao, J. Huang, Nat. Commun. 2015, 6, 7747.

[60] J. H. Heo, H. J. Han, D. Kim, T. K. Ahn, S. H. Im, Energy Environ. Sci. 2015, 8, 1602.

[61] Q. Wang, Y. Shao, Q. Dong, Z. Xiao, Y. Yuan, J. Huang, Energy Environ. Sci. 2014, 7, 2359.

[62] Y. Shao, Z. Xiao, C. Bi, Y. Yuan, J. Huang, Nat. Commun. 2014, 5, 5784.

[63] P.-W. Liang, C.-C. Chueh, S. T. Williams, A. K. Y. Jen, Adv. Energy Mater. 2015, 5, 1402321.

[64] S.-M. Dai, L.-L. Deng, M.-L. Zhang, W.-Y. Chen, P. Zhu, X. Wang, C. Li, Z. a. Tan, S.-Y. Xie, R.-B. Huang, L.-S. Zheng, Inorg. Chim. Acta 2017, DOI:10.1016/j.ica.2017.05.056.

[65] Y. Shao, Y. Yuan, J. Huang, Nat. Energy 2016, 1, 15001.

[66] Y. Xing, C. Sun, H. L. Yip, G. C. Bazan, F. Huang, Y. Cao, Nano Energy 2016, $26,7$.

[67] S. Shao, M. Abdu-Aguye, L. Qiu, L.-H. Lai, J. Liu, S. Adjokatse, F. Jahani, M. E. Kamminga, G. H. ten Brink, T. T. M. Palstra, B. J. Kooi, J. C. Hummelen, M. Antonietta Loi, Energy Environ. Sci. 2016, 9, 2444.

[68] L. Gil-Escrig, C. Momblona, M. Sessolo, H. J. Bolink, J. Mater. Chem. A 2016, 4, 3667. 


\section{WILEY-VCH}

[69] Q. Xue, Y. Bai, M. Liu, R. Xia, Z. Hu, Z. Chen, X.-F. Jiang, F. Huang, S. Yang, Y.

Matsuo, H.-L. Yip, Y. Cao, Adv. Energy Mater. 2017, 7, 1602333.

[70] C.-G. Wu, C.-H. Chiang, S. H. Chang, Nanoscale 2016, 8, 4077.

[71] Y. Lin, B. Chen, F. Zhao, X. Zheng, Y. Deng, Y. Shao, Y. Fang, Y. Bai, C. Wang, J. Huang, Adv. Mater. 2017, DOI: 10.1002/adma.201700607.

[72] X. Meng, Y. Bai, S. Xiao, T. Zhang, C. Hu, Y. Yang, X. Zheng, S. Yang, Nano Energy 2016, 30, 341.

[73] S. Chang, G. D. Han, J. G. Weis, H. Park, O. Hentz, Z. Zhao, T. M. Swager, S.

Gradecak, ACS Appl. Mater. Interfaces 2016, 8, 8511.

[74] C. Tian, E. Castro, T. Wang, G. Betancourt-Solis, G. Rodriguez, L. Echegoyen, ACS Appl. Mater. Interfaces 2016, 8, 31426.

[75] C. Tian, K. Kochiss, E. Castro, G. Betancourt-Solis, H. Han, L. Echegoyen, J. Mater. Chem. A 2017, 5, 7326.

[76] Y. Bai, Q. Dong, Y. Shao, Y. Deng, Q. Wang, L. Shen, D. Wang, W. Wei, J. Huang, Nat. Commun. 2016, 7, 12806.

[77] P. Docampo, J. M. Ball, M. Darwich, G. E. Eperon, H. J. Snaith, Nat. Commun. 2013, 4, 3761.

[78] J. Seo, S. Park, Y. Chan Kim, N. J. Jeon, J. H. Noh, S. C. Yoon, S. I. Seok, Energy Environ. Sci. 2014, 7, 2642.

[79] J. You, Y. Yang, Z. Hong, T.-B. Song, L. Meng, Y. Liu, C. Jiang, H. Zhou, W.-H. Chang, G. Li, Appl. Phys. Lett. 2014, 105, 183902.

[80] S. Bai, Z. Wu, X. Wu, Y. Jin, N. Zhao, Z. Chen, Q. Mei, X. Wang, Z. Ye, T. Song, R. Liu, S.-t. Lee, B. Sun, Nano Res. 2014, 7, 1749.

[81] X. Liu, H. Yu, L. Yan, Q. Dong, Q. Wan, Y. Zhou, B. Song, Y. Li, ACS Appl. Mater. Interfaces 2015, 7, 6230. 


\section{WILEY-VCH}

[82] P.-W. Liang, C.-Y. Liao, C.-C. Chueh, F. Zuo, S. T. Williams, X.-K. Xin, J. Lin, A. K. Y. Jen, Adv. Mater. 2014, 26, 3748.

[83] Z. Zhu, C.-C. Chueh, F. Lin, K. Y. Jen Alex, Adv. Sci. 2016, 3, 1600027.

[84] X. Liu, W. Jiao, M. Lei, Y. Zhou, B. Song, Y. Li, J. Mater. Chem. A 2015, 3, 9278.

[85] H. Azimi, T. Ameri, H. Zhang, Y. Hou, C. O. R. Quiroz, J. Min, M. Hu, Z.-G. Zhang, T. Przybilla, G. J. Matt, E. Spiecker, Y. Li, C. J. Brabec, Adv. Energy Mater. 2015, 5, 1401692.

[86] Y. Liu, M. Bag, L. A. Renna, Z. A. Page, P. Kim, T. Emrick, D. Venkataraman, T. P. Russell, Adv. Energy Mater. 2016, 6, 1501606.

[87] J. Xie, X. Yu, X. Sun, J. Huang, Y. Zhang, M. Lei, K. Huang, D. Xu, Z. Tang, C. Cui, D. Yang, Nano Energy 2016, 28, 330.

[88] X. Liu, P. Huang, Q. Dong, Z. Wang, K. Zhang, H. Yu, M. Lei, Y. Zhou, B. Song, Y. Li, Sci. China Chem. 2017, 60, 136.

[89] T. Leijtens, G. E. Eperon, S. Pathak, A. Abate, M. M. Lee, H. J. Snaith, Nat. Commun. 2013, 4, 3885.

[90] A. Abrusci, S. D. Stranks, P. Docampo, H.-L. Yip, A. K. Y. Jen, H. J. Snaith, Nano Lett. 2013, 13, 3124.

[91] K. Wojciechowski, D. Stranks Samuel, A. Abate, G. Sadoughi, A. Sadhanala, N. Kopidakis, G. Rumbles, C.-Z. Li, H. Friend Richard, K. Y. Jen Alex, J. Snaith Henry, ACS Nano 2014, 8, 12701.

[92] M. Shahiduzzaman, K. Yamamoto, Y. Furumoto, T. Kuwabara, K. Takahashi, T. Taima, Chem. Lett. 2015, 44, 1735.

[93] C. Tao, S. Neutzner, L. Colella, S. Marras, A. R. Srimath Kandada, M. Gandini, M. De Bastiani, G. Pace, L. Manna, M. Caironi, C. Bertarelli, A. Petrozza, Energy Environ. Sci. 2015, 8, 2365. 


\section{WILEY-VCH}

[94] C. Liu, K. Wang, P. Du, T. Meng, X. Yu, S. Z. D. Cheng, X. Gong, ACS Appl. Mater. Interfaces 2015, 7, 1153.

[95] W. Zhou, J. Zhen, Q. Liu, Z. Fang, D. Li, P. Zhou, T. Chen, S. Yang, J. Mater. Chem. A 2017, 5, 1724.

[96] Y. Dong, W. Li, X. Zhang, Q. Xu, Q. Liu, C. Li, Z. Bo, Small 2016, 12, 1098.

[97] T. Cao, Z. Wang, Y. Xia, B. Song, Y. Zhou, N. Chen, Y. Li, ACS Appl. Mater. Interfaces 2016, 8, 18284.

[98] Y. Li, Y. Zhao, Q. Chen, Y. Yang, Y. Liu, Z. Hong, Z. Liu, Y.-T. Hsieh, L. Meng, Y. Li, J. Am. Chem. Soc. 2015, 137, 15540.

[99] V. O. Eze, Y. Seike, T. Mori, Org. Electron. 2017, 46, 253.

[100] F. Fu, T. Feurer, T. Jager, E. Avancini, B. Bissig, S. Yoon, S. Buecheler, A. N. Tiwari, Nat. Commun. 2015, 6, 8932.

[101] M. Qin, J. Ma, W. Ke, P. Qin, H. Lei, H. Tao, X. Zheng, L. Xiong, Q. Liu, Z. Chen, J. Lu, G. Yang, G. Fang, ACS Appl. Mater. Interfaces 2016, 8, 8460.

[102] W. Ke, D. Zhao, C. Xiao, C. Wang, A. J. Cimaroli, C. R. Grice, M. Yang, Z. Li, C.-S. Jiang, M. Al-Jassim, K. Zhu, M. G. Kanatzidis, G. Fang, Y. Yan, J. Mater. Chem. A 2016, 4, 14276.

[103] X. Wang, L.-L. Deng, L.-Y. Wang, S.-M. Dai, Z. Xing, X.-X. Zhan, X.-Z. Lu, S.-Y. Xie, R.-B. Huang, L.-S. Zheng, J. Mater. Chem. A 2017, 5, 1706.

[104] L. Kegelmann, C. M. Wolff, C. Awino, F. Lang, E. L. Unger, L. Korte, T. Dittrich, D. Neher, B. Rech, S. Albrecht, ACS Appl. Mater. Interfaces 2017, 9, 17245.

[105] D. Liu, T. L. Kelly, Nat. Photonics 2014, 8, 133.

[106] W. Ke, G. Fang, Q. Liu, L. Xiong, P. Qin, H. Tao, J. Wang, H. Lei, B. Li, J. Wan, G. Yang, Y. Yan, J. Am. Chem. Soc. 2015, 137, 6730.

[107] K. Wang, Y. Shi, Q. Dong, Y. Li, S. Wang, X. Yu, M. Wu, T. Ma, J. Phys. Chem. Lett. 2015, 6, 755 . 


\section{WILEY-VCH}

[108] S. L. Fernandes, A. C. Veron, N. F. A. Neto, F. A. Nuesch, J. H. Dias da Silva, M. A. Zaghete, C. F. d. O. Graeff, Mater. Lett. 2016, 181, 103.

[109] W. Hu, T. Liu, X. Yin, H. Liu, X. Zhao, S. Luo, Y. Guo, Z. Yao, J. Wang, N. Wang, H. Lin, Z. Guo, J. Mater. Chem. A 2017, 5, 1434.

[110] S. S. Shin, W. S. Yang, J. H. Noh, J. H. Suk, N. J. Jeon, J. H. Park, J. S. Kim, W. M. Seong, S. I. Seok, Nat. Commun. 2015, 6, 7410.

[111] X. Zhao, H. Shen, Y. Zhang, X. Li, X. Zhao, M. Tai, J. Li, J. Li, H. Lin, ACS Appl. Mater. Interfaces 2016, 8, 7826.

[112] A. Bera, K. Wu, A. Sheikh, E. Alarousu, O. F. Mohammed, T. Wu, J. Phys. Chem. C 2014, 118, 28494.

[113] S. S. Shin, E. J. Yeom, W. S. Yang, S. Hur, M. G. Kim, J. Im, J. Seo, J. H. Noh, S. I. Seok, Science 2017, 356, 167.

[114] J. Liu, C. Gao, L. Luo, Q. Ye, X. He, L. Ouyang, X. Guo, D. Zhuang, C. Liao, J. Mei, W. Lau, J. Mater. Chem. A 2015, 3, 11750.

[115] L. Wang, W. Fu, Z. Gu, C. Fan, X. Yang, H. Li, H. Chen, J. Mater. Chem. C 2014, 2, 9087.

[116] K. Wojciechowski, M. Saliba, T. Leijtens, A. Abate, H. J. Snaith, Energy Environ. Sci. 2014, 7, 1142.

[117] K. Wojciechowski, T. Leijtens, S. Siprova, T. Horantner Maximilian, T.-W. Wang Jacob, J. Snaith Henry, C. Schlueter, C.-Z. Li, K. Y. Jen Alex, T.-L. Lee, J. Phys. Chem. Lett. 2015, 6, 2399.

[118] W. Ke, D. Zhao, C. R. Grice, A. J. Cimaroli, J. Ge, H. Tao, H. Lei, G. Fang, Y. Yan, J. Mater. Chem. A 2015, 3, 17971.

[119] H. Yoon, S. M. Kang, J.-K. Lee, M. Choi, Energy Environ. Sci. 2016, 9, 2262.

[120] D. Zhao, W. Ke, C. R. Grice, A. J. Cimaroli, X. Tan, M. Yang, R. W. Collins, H. Zhang, K. Zhu, Y. Yan, Nano Energy 2016, 19, 88. 


\section{WILEY-VCH}

[121] S. Collavini, I. Kosta, S. F. Voelker, G. Cabanero, H. J. Grande, R. Tena-Zaera, J. L. Delgado, ChemSusChem 2016, 9, 1263.

[122] S. Ryu, J. Seo, S. S. Shin, Y. C. Kim, N. J. Jeon, J. H. Noh, S. I. Seok, J. Mater. Chem. A 2015, 3, 3271.

[123] J. H. Kim, C.-C. Chueh, S. T. Williams, A. K. Y. Jen, Nanoscale 2015, 7, 17343.

[124] J. Lee, J. Kim, C.-L. Lee, G. Kim, T. K. Kim, H. Back, S. Jung, K. Yu, S. Hong, S.

Lee, S. Kim, S. Jeong, H. Kang, K. Lee, Adv. Energy Mater. 2017, 7, 1700226.

[125] J. Xie, X. Yu, J. Huang, X. Sun, Y. Zhang, Z. Yang, M. Lei, L. Xu, Z. Tang, C. Cui, P. Wang, D. Yang, Adv. Sci. 2017, 4, 1700018.

[126] Y.-C. Wang, X. Li, L. Zhu, X. Liu, W. Zhang, J. Fang, Adv. Energy Mater. 2017, 1701144.

[127] W. Qiu, J. P. Bastos, S. Dasgupta, T. Merckx, I. Cardinaletti, M. V. C. Jenart, C. B.

Nielsen, R. Gehlhaar, J. Poortmans, P. Heremans, I. McCulloch, D. Cheyns, J. Mater. Chem. A 2017, 5, 2466.

[128] K. Wojciechowski, I. Ramirez, T. Gorisse, O. Dautel, R. Dasari, N. Sakai, J. M.

Hardigree, S. Song, S. Marder, M. Riede, G. Wantz, H. J. Snaith, ACS Energy Lett. 2016, 1, 648.

[129] B. L. Watson, N. Rolston, K. A. Bush, T. Leijtens, M. D. McGehee, R. H. Dauskardt, ACS Appl. Mater. Interfaces 2016, 8, 25896.

[130] E. Edri, S. Kirmayer, S. Mukhopadhyay, K. Gartsman, G. Hodes, D. Cahen, Nat. Commun. 2014, 5, 4461.

[131] E. Edri, S. Kirmayer, A. Henning, S. Mukhopadhyay, K. Gartsman, Y. Rosenwaks, G. Hodes, D. Cahen, Nano Lett. 2014, 14, 1000.

[132] G. E. Eperon, S. D. Stranks, C. Menelaou, M. B. Johnston, L. M. Herz, H. J. Snaith, Energy Environ. Sci. 2014, 7, 982. 


\section{WILEY-VCH}

[133] G. A. Elbaz, D. B. Straus, O. E. Semonin, T. D. Hull, D. W. Paley, P. Kim, J. S. Owen, C. R. Kagan, X. Roy, Nano Lett. 2017, 17, 1727.

[134] J. Xu, A. Buin, A. H. Ip, W. Li, O. Voznyy, R. Comin, M. Yuan, S. Jeon, Z. Ning, J. J. McDowell, P. Kanjanaboos, J.-P. Sun, X. Lan, L. N. Quan, D. H. Kim, I. G. Hill, P.

Maksymovych, E. H. Sargent, Nat. Commun. 2015, 6, 7081.

[135] C.-H. Chiang, C.-G. Wu, Nat. Photonics 2016, 10, 196.

[136] Y. Liu, R. Jia, Y. Wang, Z. Hu, Y. Zhang, T. Pang, Y. Zhu, S. Luan, ACS Appl. Mater. Interfaces 2017, 9, 15638.

[137] Y. Zhang, Y. Liu, T. Pang, Z. Hu, Y. Zhu, S. Luan, R. Jia, J. Phys. D: Appl. Phys. 2017, DOI: 10.1088/1361.

[138] C. Ran, Y. Chen, W. Gao, M. Wang, L. Dai, J. Mater. Chem. A 2016, 4, 8566.

[139] Y. Zhong, R. Munir, A. H. Balawi, A. D. Sheikh, L. Yu, M.-C. Tang, H. Hu, F. Laquai, A. Amassian, ACS Energy Lett. 2016, 1, 1049.

[140] Y. Wu, X. Yang, W. Chen, Y. Yue, M. Cai, F. Xie, E. Bi, A. Islam, L. Han, Nat. Energy 2016, 1, 16148.

[141] R. Sandoval-Torrientes, J. Pascual, I. Garcia-Benito, S. Collavini, I. Kosta, R. TenaZaera, N. Martin, J. L. Delgado, ChemSusChem 2017, 10, 2023.

[142] K. Wang, C. Liu, P. Du, J. Zheng, X. Gong, Energy Environ. Sci. 2015, 8, 1245.

[143] C. Liu, W. Li, H. Li, C. Zhang, J. Fan, Y. Mai, Nanoscale 2017, 9, 13967.

[144] J. Pascual, I. Kosta, T. Tuyen Ngo, A. Chuvilin, G. Cabanero, H. J. Grande, E. M. Barea, I. Mora-Sero, J. L. Delgado, R. Tena-Zaera, ChemSusChem 2016, 9, 2679.

[145] F. Zhang, W. Shi, J. Luo, N. Pellet, C. Yi, X. Li, X. Zhao, T. J. S. Dennis, X. Li, S. Wang, Y. Xiao, S. M. Zakeeruddin, D. Bi, M. Grätzel, Adv. Mater. 2017, 29, 1606806. [146] M. Li, Y.-H. Chao, T. Kang, Z.-K. Wang, Y.-G. Yang, S.-L. Feng, Y. Hu, X.-Y. Gao, L.-S. Liao, C.-S. Hsu, J. Mater. Chem. A 2016, 4, 15088. 


\section{WILEY-VCH}

[147] X. Liu, F. Lin, C.-C. Chueh, Q. Chen, T. Zhao, P.-W. Liang, Z. Zhu, Y. Sun, A. K. Y. Jen, Nano Energy 2016, 30, 417. 


\section{WILEY-VCH}

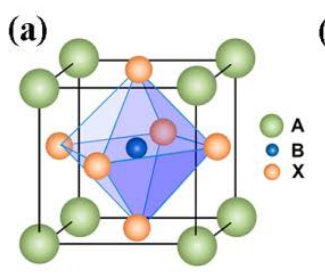

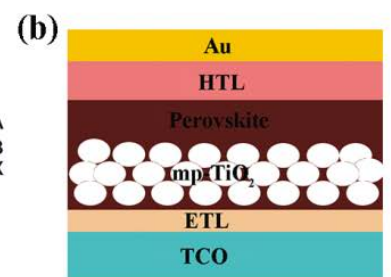

Mesoporous structure

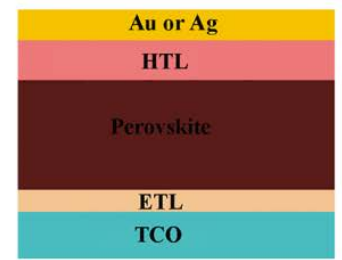

n-i-p planar structure

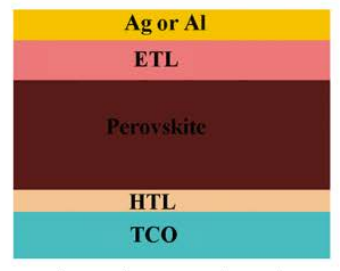

p-i-n planar structure

Figure 1. (a) The crystal structure of the $\mathrm{ABX}_{3}$ perovskite material. Reproduced with permission. ${ }^{[7]}$ Copyright 2014, American Chemical Society. (b) Device structures of perovskite solar cells. 


\section{WILEY-VCH}

(a)
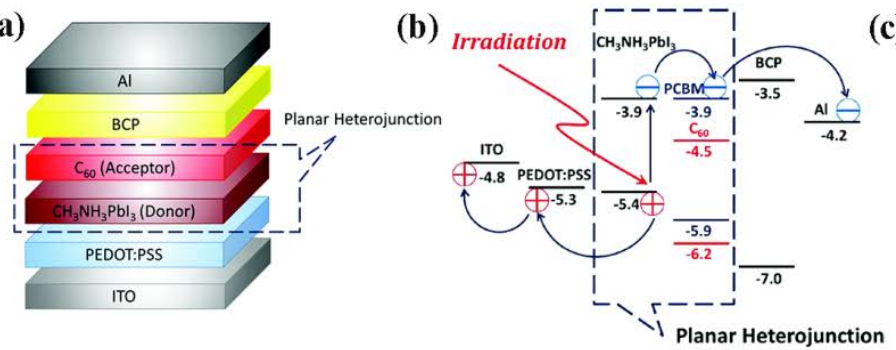

(c)

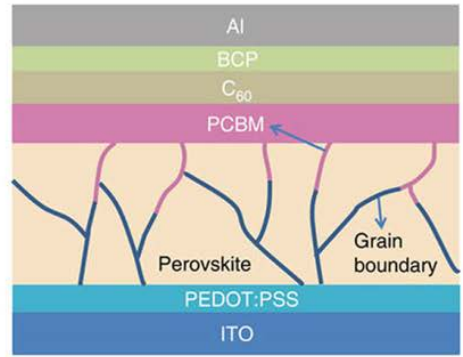

Figure 2. (a) The device structure of p-i-n perovskite solar cells. (b) Scheme of the energy levels of each layer in the device. Reproduced with permission. ${ }^{[54]}$ Copyright 2013, WileyVCH. (c) Schematic device structure of PSCs showing the diffusion of fullerene into the perovskite grain boundaries. Reproduced with permission. ${ }^{[62]}$ Copyright 2014, Nature Publishing Group. 


\section{WILEY-VCH}
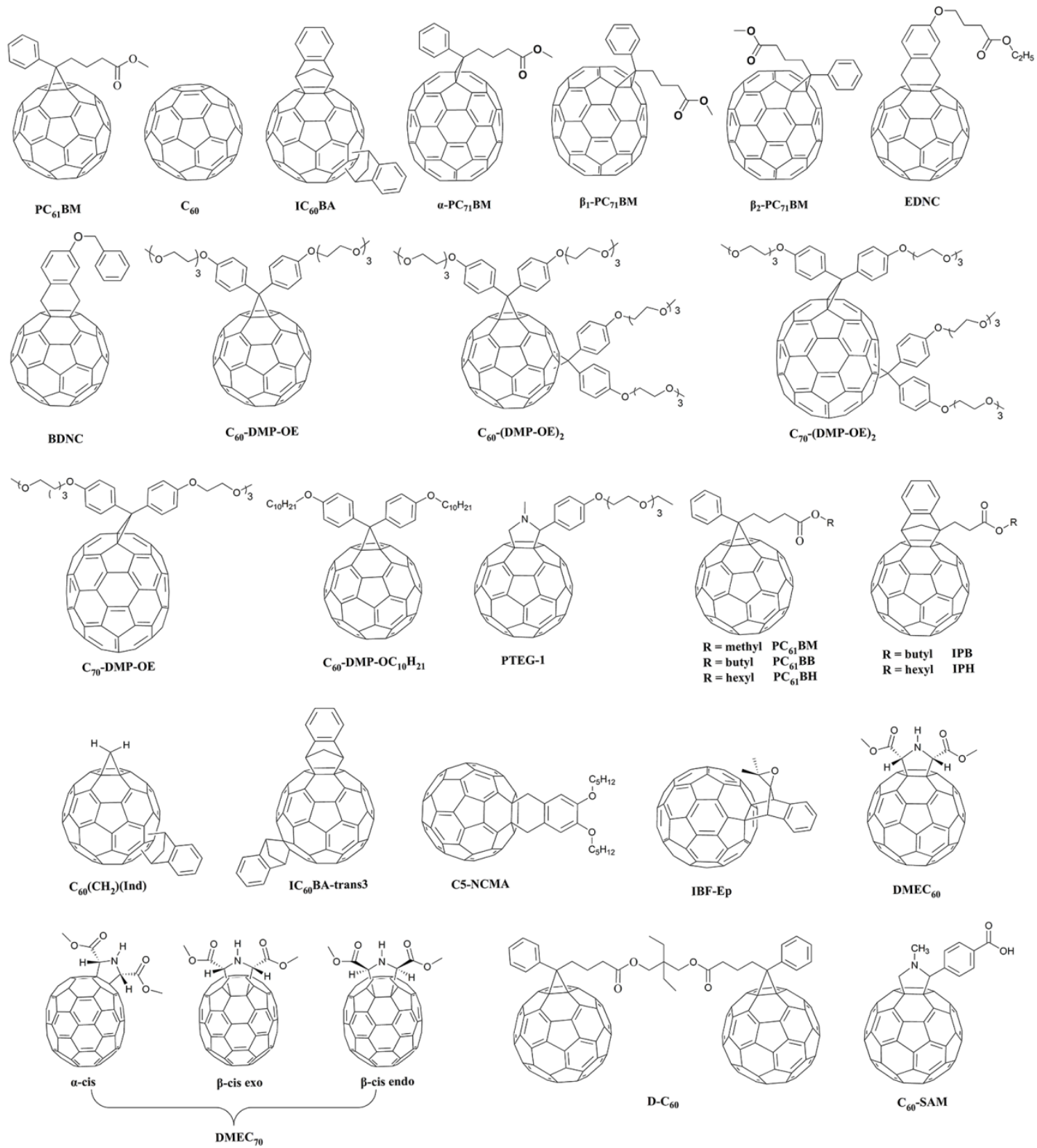

Figure 3. Molecular structures of fullerene derivatives as electron transport layers for p-i-n PSCs. 


\section{WILEY-VCH}

(a)

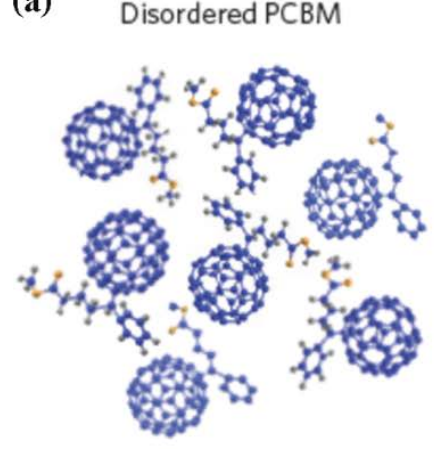

Ordered PCBM

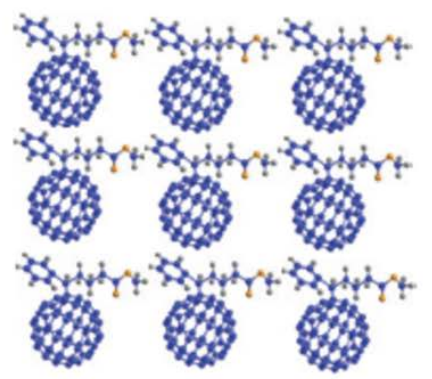

(b)

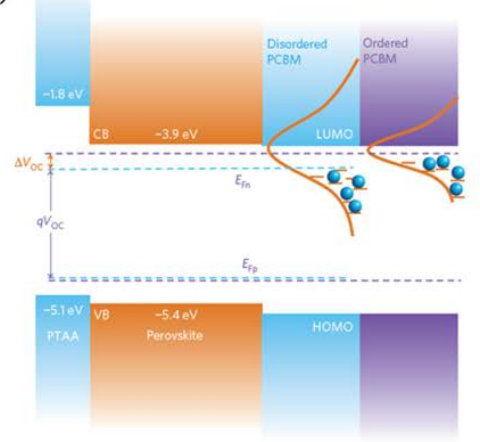

Figure 4. (a) Schematic of disordered and ordered PC ${ }_{61} B M$ structures. (b) Schematic illustration of how energy disorder of the $\mathrm{PC}_{61} \mathrm{BM}$ layer influences the device $V_{\text {oc }}$.

Reproduced with permission. ${ }^{[65]}$ Copyright 2016, Nature Publishing Group. 


\section{WILEY-VCH}

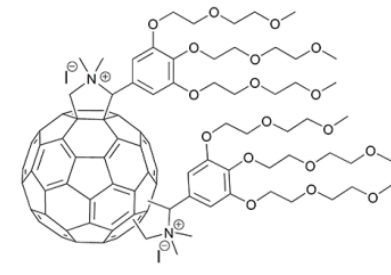

Bis- $\mathrm{C}_{60}$

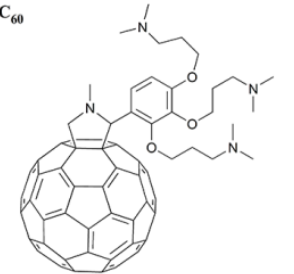

$\mathrm{C}_{60}=\mathrm{N}$

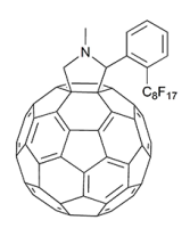

F- $\mathrm{C}_{60}$

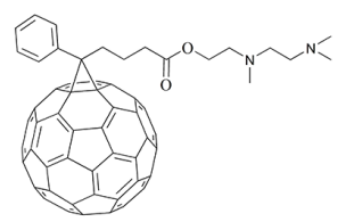

PCBDAN

PCBC
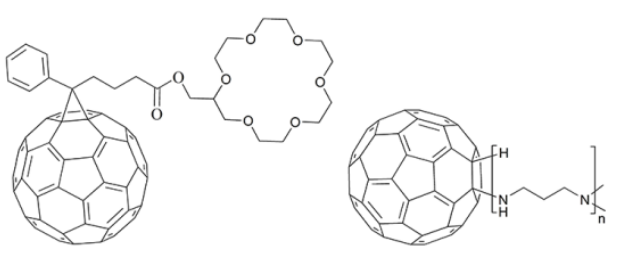

DMAPA-C 60

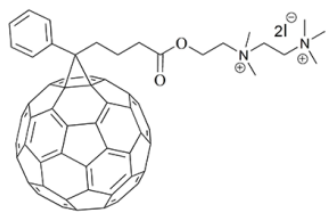

PCBDANI

Figure 5. Molecular structures of fullerene derivatives as cathode buffer layers for p-i-n PSCs. 


\section{WILEY-VCH}

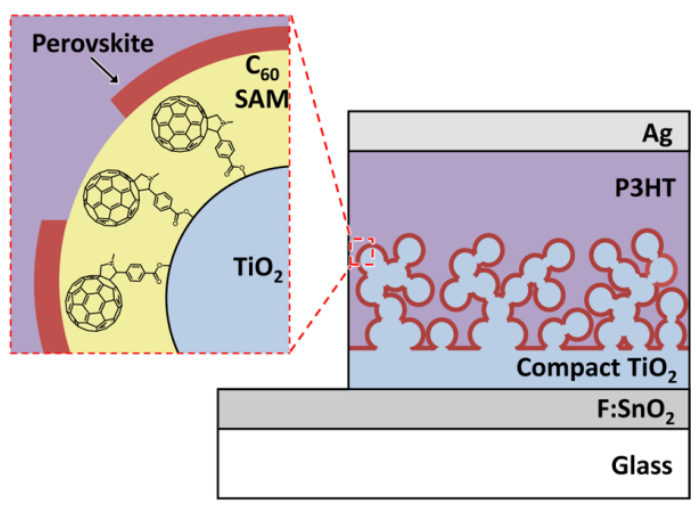

Figure 6. Schematic of device structure and the binding of $\mathrm{C}_{60}-\mathrm{SAM}$ to $\mathrm{TiO}_{2}$ surface.

Reproduced with permission. ${ }^{[90]}$ Copyright 2013, American Chemical Society. 


\section{WILEY-VCH}
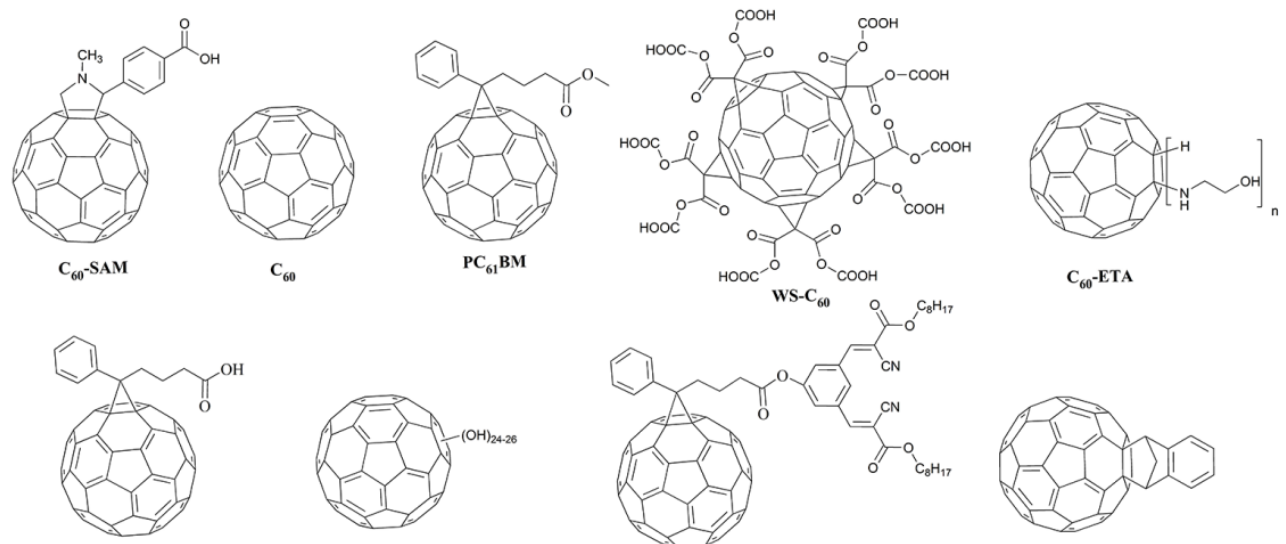

PCBA

$\mathrm{C}_{60}(\mathrm{OH})_{24-26}$

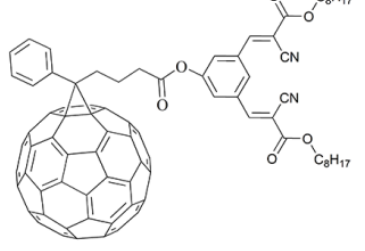

PCBB-2CN-2C8

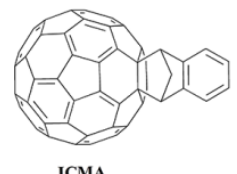

Figure 7. Molecular structures of fullerene derivatives as interfacial modification layers for ni-p PSCs. 


\section{WILEY-VCH}
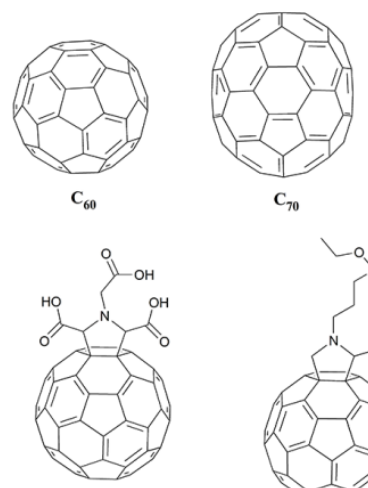

CPTA
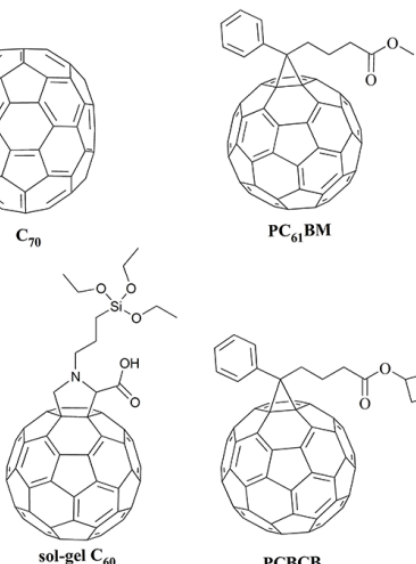
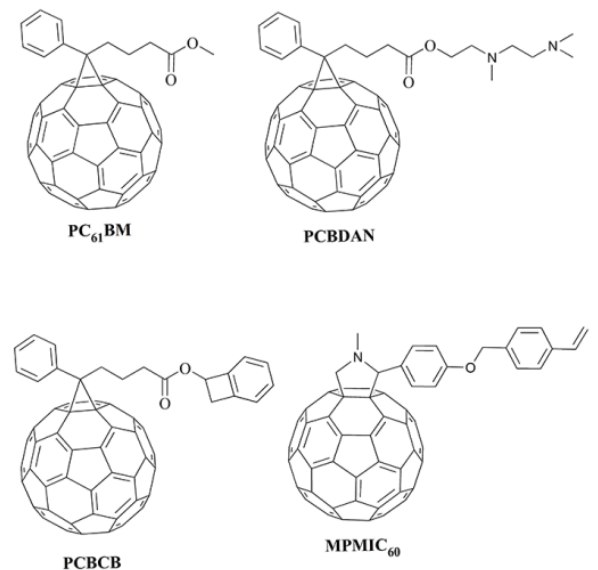

Figure 8. Molecular structures of fullerene derivatives as electron transport layers for n-i-p PSCs. 


\section{WILEY-VCH}

a

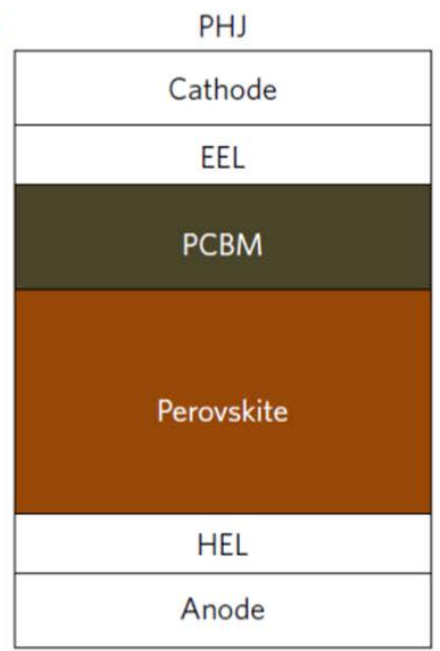

b

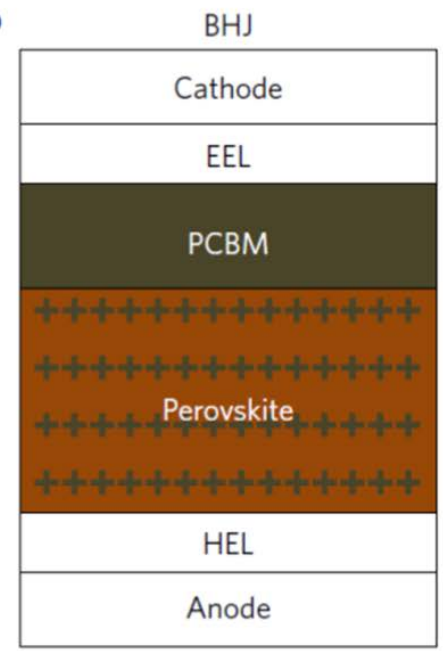

C

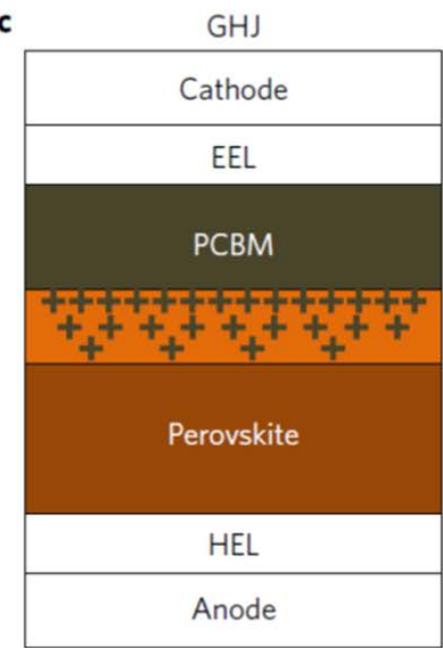

Figure 9. Schematic of three types p-i-n PSCs. (a) Planar heterojunction, PHJ. (b) Bulk heterojunction, BHJ. (c) Graded heterojunction, GHJ. Reproduced with permission. ${ }^{[140]}$ Copyright 2016, Nature Publishing Group. 


\section{WILEY-VCH}
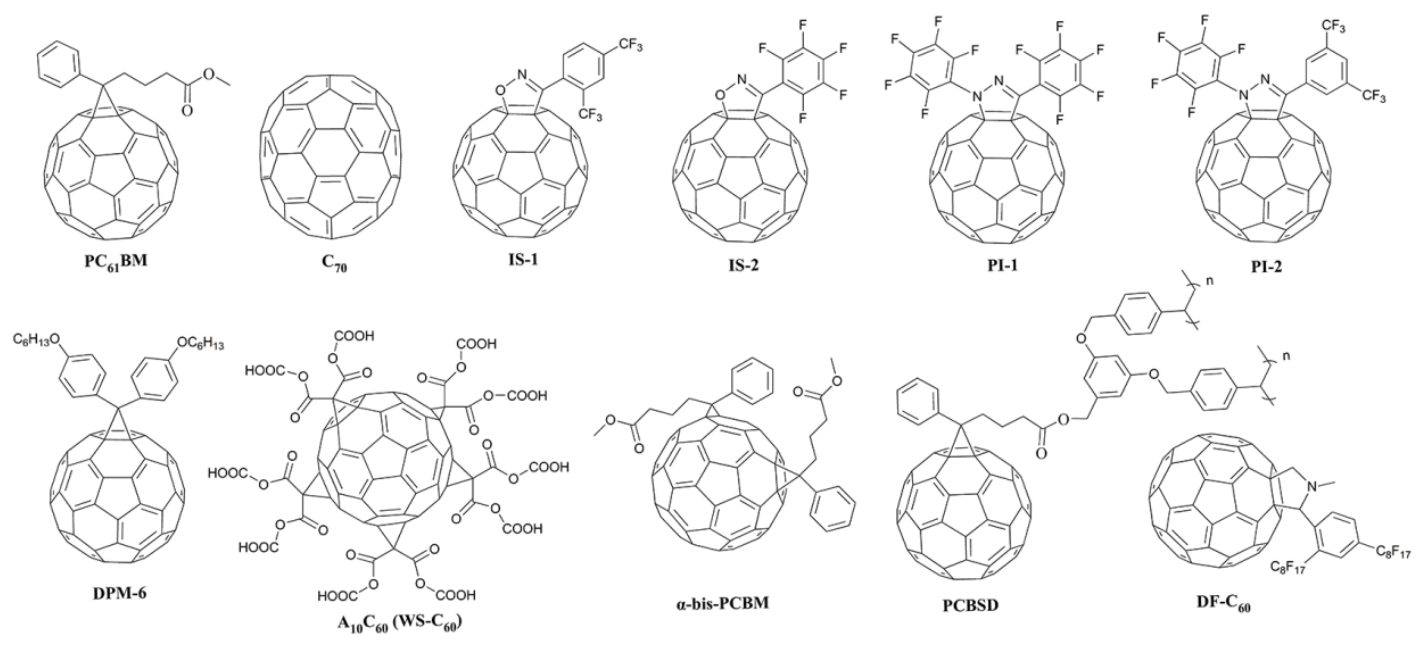

Figure 10. Molecular structures of fullerene derivatives in perovskite-fullerene heterojunction PSCs. 


\section{WILEY-VCH}

Table 1. Photovoltaic performances of p-i-n PSCs with various fullerene derivatives as ETLs.

\begin{tabular}{|c|c|c|c|c|c|c|c|c|}
\hline$\overline{E T L}$ & $\begin{array}{l}\text { LUMO }[\mathrm{eV}, \\
\left.\text { vs } \mathrm{PC}_{61} \mathrm{BM}\right]^{\mathrm{a})}\end{array}$ & $\begin{array}{l}\mu_{\mathrm{e}} \\
{\left[\mathrm{cm}^{2} \mathrm{~V}^{-1} \mathrm{~s}^{-1}\right]^{\mathrm{b})}}\end{array}$ & active layer & $\begin{array}{l}V_{\text {oc }} \\
{[\mathrm{V}]^{\mathrm{d})}}\end{array}$ & $\begin{array}{l}J_{\mathrm{sc}} \\
{\left[\mathrm{mA} / \mathrm{cm}^{2}\right]^{\mathrm{d})}}\end{array}$ & $\begin{array}{l}\mathrm{FF} \\
{[\%]^{\mathrm{d})}}\end{array}$ & $\begin{array}{l}\text { PCE } \\
{[\%]^{\mathrm{d})}}\end{array}$ & Ref. \\
\hline$\overline{\mathrm{PC}_{61} \mathrm{BM}}$ & 0 & $1.3 \times 10^{-3}$ & $\mathrm{MAPbI}_{3}$ & 1.07 & 22.0 & 76.8 & 18.1 & 59 \\
\hline $\mathrm{PC}_{71} \mathrm{BM}$ & 0 & $1.0 \times 10^{-3}$ & $\mathrm{MAPbI}_{3}$ & 0.952 & 23.37 & 78.96 & 17.56 & 57 \\
\hline $\mathrm{C}_{60}$ & -0.1 & $1.6^{\mathrm{c})}$ & $\mathrm{MAPbI}_{3}$ & 0.92 & 21.07 & 80 & 15.44 & 63 \\
\hline $\mathrm{IC}_{60} \mathrm{BA}$ & 0.2 & $6.9 \times 10^{-3 c)}$ & $\mathrm{MAPbI}_{3}$ & 0.95 & 11.27 & 75 & 8.06 & 63 \\
\hline EDNC & 0.05 & $8.5 \times 10^{-5}$ & $\mathrm{MAPbI}_{3}$ & 0.95 & 19.85 & 66.92 & 12.64 & 64 \\
\hline BDNC & 0.05 & $7.7 \times 10^{-5}$ & $\mathrm{MAPbI}_{3}$ & 0.93 & 16.17 & 48.72 & 7.36 & 64 \\
\hline $\mathrm{C}_{60}-\mathrm{DPM}-\mathrm{OE}$ & -0.01 & $5.0 \times 10^{-4}$ & $\begin{array}{l}\mathrm{MAPbI}_{3-} \\
{ }_{x} \mathrm{Cl}_{x}\end{array}$ & 0.96 & 21.4 & 76 & 15.5 & 66 \\
\hline $\mathrm{C}_{60}-(\mathrm{DPM}-\mathrm{OE})_{2}$ & -0.12 & $1.8 \times 10^{-5}$ & $\begin{array}{l}\mathrm{MAPbI}_{3-} \\
{ }_{x} \mathrm{Cl}_{x}\end{array}$ & 0.93 & 20.7 & 71 & 13.8 & 66 \\
\hline $\mathrm{C}_{70}-\mathrm{DPM}-\mathrm{OE}$ & 0.01 & $3.3 \times 10^{-4}$ & $\begin{array}{l}\mathrm{MAPbI}_{3-} \\
{ }_{x} \mathrm{Cl}_{x}\end{array}$ & 0.97 & 21.9 & 75 & 16.0 & 66 \\
\hline $\mathrm{C}_{70}-(\mathrm{DPM}-\mathrm{OE})_{2}$ & -0.14 & $1.7 \times 10^{-5}$ & $\begin{array}{l}\mathrm{MAPbI}_{3-} \\
{ }_{x} \mathrm{Cl}_{\mathrm{x}}\end{array}$ & 0.94 & 21.0 & 71 & 14.0 & 66 \\
\hline $\begin{array}{l}\mathrm{C}_{60} \text {-DPM- } \\
\mathrm{OC}_{10} \mathrm{H}_{21}\end{array}$ & 0.06 & $1.1 \times 10^{-4}$ & $\begin{array}{l}\mathrm{MAPbI}_{3-} \\
{ }_{x} \mathrm{Cl}_{\mathrm{x}}\end{array}$ & 0.90 & 19.9 & 60 & 10.8 & 66 \\
\hline PTEG-1 & 0 & - & $\begin{array}{l}\mathrm{MAPbI}_{3-} \\
{ }_{x} \mathrm{Cl}_{\mathrm{x}}\end{array}$ & 0.94 & 20.63 & 81 & 15.71 & 67 \\
\hline $\mathrm{PC}_{61} \mathrm{BB}$ & 0 & - & $\mathrm{MAPbI}_{3}$ & 1.090 & 16.02 & 76 & 13.27 & 68 \\
\hline $\mathrm{PC}_{61} \mathrm{BH}$ & 0 & - & $\mathrm{MAPbI}_{3}$ & 1.097 & 15.92 & 79 & 13.75 & 68 \\
\hline IPB & 0.03 & - & $\mathrm{MAPbI}_{3}$ & 1.102 & 16.28 & 78 & 14.02 & 68 \\
\hline IPH & 0.03 & - & $\mathrm{MAPbI}_{3}$ & 1.107 & 16.70 & 79 & 14.64 & 68 \\
\hline $\mathrm{C}_{60}\left(\mathrm{CH}_{2}\right)(\mathrm{Ind})$ & 0.14 & $3 \times 10^{-3}$ & $\mathrm{MAPbI}_{3}$ & 1.13 & 20.4 & 80.0 & 18.1 & 69 \\
\hline $\mathrm{IC}_{60} \mathrm{BA}$ & 0.2 & $4.5 \times 10^{-5}$ & $\mathrm{MAPbBr}_{3}$ & 1.61 & 6.04 & 77 & 7.50 & 70 \\
\hline
\end{tabular}


WILEY-VCH

\begin{tabular}{|c|c|c|c|c|c|c|c|c|}
\hline $\mathrm{IC}_{60} \mathrm{BA}-\operatorname{tran} 3$ & 0.2 & $3 \times 10^{-4}$ & $\begin{array}{l}\left(\mathrm{FA}_{0.83} \mathrm{MA}_{0 .}\right. \\
\left.{ }_{17}\right)_{0.95} \mathrm{Cs}_{0.05} \mathrm{P} \\
\mathrm{b}\left(\mathrm{I}_{0.6} \mathrm{Br}_{0.4}\right)_{3}\end{array}$ & 1.21 & 19.7 & 77.5 & 18.5 & 71 \\
\hline C5-NCMA & 0.05 & $1.59 \times 10^{-3}$ & $\mathrm{MAPbI}_{3}$ & 1.08 & 20.68 & 79.1 & 17.6 & 72 \\
\hline IBF-Ep & 0.02 & - & $\begin{array}{l}\mathrm{MAPbI}_{3-} \\
{ }_{x} \mathrm{Cl}_{\mathrm{x}}\end{array}$ & 0.86 & 16.9 & 62 & 9.0 & 73 \\
\hline DMEC $_{60}$ & 0.02 & $7.21 \times 10^{-4}$ & $\mathrm{MAPbI}_{3}$ & 0.92 & 21.73 & 75.8 & 15.2 & 74 \\
\hline $\mathrm{DMEC}_{70}$ & 0.01 & $9.07 \times 10^{-4}$ & $\mathrm{MAPbI}_{3}$ & 0.95 & 22.44 & 77.1 & 16.4 & 74 \\
\hline D-C 60 & 0.02 & $9.83 \times 10^{-4}$ & $\mathrm{MAPbI}_{3}$ & 0.96 & 21.89 & 78.8 & 16.6 & 75 \\
\hline $\begin{array}{l}\mathrm{C}_{60} \text {-SAM doped } \\
\text { with MAI }\end{array}$ & - & - & $\mathrm{MAPbI}_{3}$ & 1.07 & 22.6 & 80.6 & 19.5 & 76 \\
\hline
\end{tabular}

${ }^{\mathrm{a})}$ The LUMO energy levels of fullerene derivatives with respect to $\mathrm{PC}_{61} \mathrm{BM}$ reference were measured by cyclic voltammetry under the same conditions. The LUMO of $\mathrm{PC}_{61} \mathrm{BM}$ is -3.91 $\mathrm{eV}$; ${ }^{\mathrm{b})}$ Measured space-charge limited current (SCLC) electron mobility of fullerene films; c) The electron mobility was determined by field-effect transistor measurements; ${ }^{\mathrm{d})}$ Values were obtained from $J-V$ curves in the reverse scan direction. 
Table 2. Photovoltaic performances of p-i-n PSCs with various fullerene derivatives as CBLs.

\begin{tabular}{|c|c|c|c|c|c|c|}
\hline Device structure & $\begin{array}{l}\Phi \\
{[\mathrm{eV}]^{\mathrm{a})}}\end{array}$ & $\begin{array}{l}V_{\text {oc }} \\
{[\mathrm{V}]^{\mathrm{c})}}\end{array}$ & $\begin{array}{l}J_{\mathrm{sc}} \\
{\left[\mathrm{mA} / \mathrm{cm}^{2}\right]^{\mathrm{c})}}\end{array}$ & $\begin{array}{l}\text { FF } \\
{[\%]^{\mathrm{c})}}\end{array}$ & $\begin{array}{l}\text { PCE } \\
{[\%]^{\mathrm{c})}}\end{array}$ & Ref. \\
\hline ITO/PEDOT:PSS/MAPbI ${ }_{3-\mathrm{x}} \mathrm{Cl}_{\mathrm{x}} / \mathrm{PC}_{61} \mathrm{BM} / \mathrm{Bis} \mathrm{C}_{60} / \mathrm{Ag}$ & - & 0.92 & 17.5 & 73 & 11.8 & 82 \\
\hline ITO/PEDOT:PSS/MAPbI ${ }_{3-\mathrm{x}} \mathrm{Cl}_{\mathrm{x}} / \mathrm{PC}_{61} \mathrm{BM} / \mathrm{Bis}_{-} \mathrm{C}_{60}: \mathrm{F}-$ & - & 0.97 & 21.2 & 75.4 & 15.5 & 83 \\
\hline $\mathrm{C}_{60} / \mathrm{Ag}$ & & & & & & \\
\hline ITO/PEDOT:PSS/MAPbI ${ }_{3-\mathrm{x}} \mathrm{Cl}_{\mathrm{x}} / \mathrm{PC}_{61} \mathrm{BM} / \mathrm{PCBC} / \mathrm{Al}$ & - & 0.98 & 22.08 & 69.7 & 15.08 & 84 \\
\hline ITO/PEDOT:PSS/MAPbI ${ }_{3-\mathrm{x}} \mathrm{Cl}_{\mathrm{x}} / \mathrm{PC}_{61} \mathrm{BM} / \mathrm{DMAPA}-\mathrm{C}_{60} / \mathrm{Ag}$ & -3.97 & 0.97 & 17.9 & 77 & 13.4 & 85 \\
\hline ITO/PEDOT:PSS/MAPbI $3 / \mathrm{PC}_{61} \mathrm{BM} / \mathrm{C}_{60}-\mathrm{N} / \mathrm{Ag}$ & -3.65 & 1.03 & 20.50 & 73.5 & 15.5 & 86 \\
\hline $\mathrm{FTO} / \mathrm{NiO} / \mathrm{MAPbI}_{3} / \mathrm{PC}_{61} \mathrm{BM} / \mathrm{PCBDAN} / \mathrm{Ag}$ & -4.14 & 1.08 & 20.71 & 77 & 17.2 & 87 \\
\hline ITO/PEDOT:PSS/MAPbI ${ }_{3-\mathrm{x}} \mathrm{Cl}_{\mathrm{x}} / \mathrm{PC}_{61} \mathrm{BM} / \mathrm{PCBDANI} / \mathrm{Al}$ & $-3.68^{\mathrm{b})}$ & 0.92 & 21.20 & 79.5 & 15.45 & 88 \\
\hline ITO/PEDOT:PSS/MAPbI ${ }_{3-}$ & -3.60 & 0.91 & 21.28 & 81.0 & 15.71 & 88 \\
\hline
\end{tabular}

${ }^{\mathrm{a})}$ Work function of the modified cathode; ${ }^{\mathrm{b}}$ LUMO energy level of CBL; ${ }^{\mathrm{c}}$ Values were obtained from $J$ - $V$ curves in the reverse scan direction. 
Table 3. Photovoltaic performances of n-i-p PSCs with various fullerene derivatives as interfacial modification layers.

\begin{tabular}{|c|c|c|c|c|c|c|}
\hline Device structure & $\begin{array}{l}\text { LUMO } \\
{[\mathrm{eV}]^{\mathrm{a})}}\end{array}$ & $\begin{array}{c}V_{\text {oc }} \\
{[\mathrm{V}]^{\mathrm{b})}}\end{array}$ & $\begin{array}{c}J_{\mathrm{sc}} \\
{\left[\mathrm{mA} / \mathrm{cm}^{2}\right]^{\mathrm{b})}}\end{array}$ & $\begin{array}{c}\mathrm{FF} \\
{[\%]^{\mathrm{b})}}\end{array}$ & $\begin{array}{l}\text { PCE } \\
{[\%]^{b)}}\end{array}$ & Ref. \\
\hline $\mathrm{FTO} / \mathrm{TiO}_{2} / \mathrm{C}_{60}-\mathrm{SAM} / \mathrm{MAPbI}_{3} /$ spiro-OMeTAD/Au & -3.95 & 1.04 & 22.1 & 75 & 17.3 & 91 \\
\hline ITO/TiO ${ }_{x} / \mathrm{C}_{60} / \mathrm{MAPbI}_{3} /$ spiro-OMeTAD/Ag & -4.50 & 0.93 & 15.17 & 69 & 9.51 & 92 \\
\hline $\mathrm{FTO} / \mathrm{TiO}_{\mathrm{x}} / \mathrm{PC}_{61} \mathrm{BM} / \mathrm{MAPbI}_{3} /$ spiro-OMeTAD/Au & - & 1.11 & 21.0 & 76.6 & 17.9 & 93 \\
\hline $\mathrm{ITO} / \mathrm{TiO}_{\mathrm{x}} / \mathrm{PC}_{61} \mathrm{BM} / \mathrm{WS}-\mathrm{C}_{60} / \mathrm{MAPbI}_{3} / \mathrm{P} 3 \mathrm{HT} / \mathrm{MoO}_{\mathrm{x}} / \mathrm{Al}$ & -4.1 & 0.95 & 27.4 & 56.3 & 14.6 & 94 \\
\hline $\mathrm{FTO} / \mathrm{TiO}_{2} / \mathrm{PC}_{61} \mathrm{BM} / \mathrm{C}_{60}-\mathrm{ETA} / \mathrm{MAPbI}_{3} /$ spiro-OMeTAD/Au & -3.72 & 1.05 & 22.90 & 66.46 & 16.31 & 95 \\
\hline $\mathrm{FTO} / \mathrm{TiO}_{2} / \mathrm{PCBA} / \mathrm{MAPbI}_{3} /$ spiro-OMeTAD/Ag & -4.2 & 1.16 & 21.38 & 72 & 17.76 & 96 \\
\hline $\mathrm{ITO} / \mathrm{TiO}_{2} / \mathrm{C}_{60}(\mathrm{OH})_{24-26} / \mathrm{MAPbI}_{3-\mathrm{x}} \mathrm{Cl}_{\mathrm{x}} / \mathrm{P} 3 \mathrm{HT} / \mathrm{MoO}_{\mathrm{x}} / \mathrm{Ag}$ & -4.27 & 0.96 & 21.14 & 72.12 & 14.69 & 97 \\
\hline $\mathrm{ITO} / \mathrm{TiO}_{2} / \mathrm{PCBB}-2 \mathrm{CN}-2 \mathrm{C} 8 / \mathrm{MAPbI}_{3} /$ spiro-OMeTAD/Au & -4.01 & 1.06 & 20.68 & 79.1 & 17.35 & 98 \\
\hline $\mathrm{FTO} / \mathrm{WO}_{\mathrm{x}} / \mathrm{C}_{60} / \mathrm{MAPbI}_{3} /$ spiro-OMeTAD/Au & -3.9 & 0.93 & 22.15 & 78 & 16.07 & 99 \\
\hline $\mathrm{FTO} / \mathrm{ZnO} / \mathrm{PC}_{61} \mathrm{BM} / \mathrm{MAPbI}_{3} /$ spiro-OMeTAD/Au & - & 1.103 & 17.5 & 74.6 & 14.4 & 100 \\
\hline $\mathrm{FTO} / \mathrm{In}_{2} \mathrm{O}_{3} / \mathrm{PC}_{61} \mathrm{BM} / \mathrm{MAPbI}_{3} /$ spiro-OMeTAD/Au & - & 1.08 & 20.06 & 68.5 & 14.83 & 101 \\
\hline $\mathrm{FTO} / \mathrm{SnO}_{2} / \mathrm{PC}_{61} \mathrm{BM} / \mathrm{MAPbI}_{3} /$ spiro-OMeTAD/Au & - & 1.12 & 22.61 & 75.8 & 19.12 & 102 \\
\hline $\mathrm{FTO} / \mathrm{SnO}_{2} / \mathrm{C}_{60} / \mathrm{MAPbI}_{3} /$ spiro-OMeTAD/Au & - & 1.10 & 21.21 & 75.55 & 17.70 & 102 \\
\hline $\mathrm{FTO} / \mathrm{CeO}_{\mathrm{x}} / \mathrm{PC}_{61} \mathrm{BM} / \mathrm{MAPbI}_{3} /$ spiro-OMeTAD/Ag & - & 1.06 & 23.25 & 69.14 & 17.04 & 103 \\
\hline
\end{tabular}




\begin{tabular}{lllllll}
\hline $\mathrm{ITO}_{\mathrm{SnO}_{2} / \mathrm{PC}_{61} \mathrm{BM} / \mathrm{MAPbI}_{3} / \mathrm{spiro}-\mathrm{OMeTAD} / \mathrm{Au}}$ & -3.95 & 1.04 & 20.3 & 64.7 & 13.8 & 104 \\
$\mathrm{ITO} / \mathrm{TiO}_{2} / \mathrm{PC}_{61} \mathrm{BM} / \mathrm{MAPbI}_{3} / \mathrm{spiro-OMeTAD} / \mathrm{Au}$ & -3.95 & 1.11 & 22.23 & 74.6 & 18.4 & 104 \\
\hline
\end{tabular}

a)The LUMO energy level of fullerene derivative as interfacial modification layer; ${ }^{\text {b)} V a l u e s}$ were obtained from $J$ - $V$ curves in the reverse scan direction.

Table 4. Photovoltaic performances of n-i-p PSCs with various fullerene derivatives as ETLs.

\begin{tabular}{|c|c|c|c|c|c|c|c|c|}
\hline$\overline{\text { ETL }}$ & $\begin{array}{l}\text { LUMO } \\
{[\mathrm{eV}]}\end{array}$ & $\begin{array}{l}\mu_{\mathrm{e}} \\
{\left[\mathrm{cm}^{2} \mathrm{~V}^{-1} \mathrm{~s}^{-1}\right]^{\mathrm{a})}}\end{array}$ & active layer & $\begin{array}{l}V_{\text {oc }} \\
{[\mathrm{V}]^{\mathrm{c})}}\end{array}$ & $\begin{array}{l}J_{\mathrm{sc}} \\
{\left[\mathrm{mA} / \mathrm{cm}^{2}\right]^{\mathrm{c})}}\end{array}$ & $\begin{array}{l}\text { FF } \\
{[\%]^{c)}}\end{array}$ & $\begin{array}{l}\text { PCE } \\
{[\%]^{\mathrm{c})}}\end{array}$ & Ref. \\
\hline $\mathrm{C}_{60}$ & - & - & $\mathrm{MAPbI}_{3}$ & 1.07 & 19.6 & 69 & 14.5 & 117 \\
\hline $\mathrm{C}_{60}$ & -4.5 & - & $\mathrm{MAPbI}_{3}$ & 1.09 & 23.67 & 73.95 & 19.11 & 119 \\
\hline $\mathrm{C}_{70}$ & -4.5 & - & $\mathrm{MAPbI}_{3}$ & 1.03 & 18.6 & 77.7 & 14.9 & 120 \\
\hline $\mathrm{C}_{60}$ & - & $1.6^{\mathrm{b})}$ & $\mathrm{MAPbI}_{3}$ & 0.993 & 15.4 & 75 & 11.4 & 121 \\
\hline $\mathrm{C}_{70}$ & - & $1.3 \times 10^{-3 \mathrm{~b})}$ & $\mathrm{MAPbI}_{3}$ & 1.005 & 14.5 & 69 & 10.0 & 121 \\
\hline $\mathrm{PC}_{61} \mathrm{BM}$ & -4.2 & $6.1 \times 10^{-2 b)}$ & $\mathrm{MAPbI}_{3}$ & 0.98 & 21.8 & 72 & 15.3 & 122 \\
\hline $\mathrm{PC}_{61} \mathrm{BM}:$ PEIE & -4.0 & - & $\mathrm{MAPbI}_{3}$ & 1.10 & 20.73 & 79 & 18.1 & 124 \\
\hline $\mathrm{PC}_{61} \mathrm{BM}: \mathrm{PCBDAN}$ & -4.1 & - & $\mathrm{MAPbI}_{3}$ & 1.08 & 21.70 & 77.3 & 18.1 & 125 \\
\hline СРТА & -3.9 & $5.4 \times 10^{-3}$ & $\mathrm{MAPbI}_{3}$ & 1.10 & 22.06 & 75.61 & 18.39 & 126 \\
\hline $\mathrm{PC}_{61} \mathrm{BM}$ & - & $2.1 \times 10^{-3}$ & $\mathrm{MAPbI}_{3}$ & 1.05 & 19.17 & 60.73 & 12.27 & 126 \\
\hline Crosslinked $\mathrm{PC}_{61} \mathrm{BM}$ & - & - & $\mathrm{MAPbI}_{3}$ & 0.99 & 20.0 & 74.6 & 14.9 & 127 \\
\hline Sol-gel C 60 & - & $3.8 \times 10^{-4}$ & $\mathrm{MAPbI}_{3-\mathrm{x}} \mathrm{Cl}_{\mathrm{x}}$ & 1.07 & 23.0 & 73 & 17.9 & 128 \\
\hline РСВСВ & - & $5.9 \times 10^{-3}$ & $\mathrm{MAPbI}_{3-\mathrm{x}} \mathrm{Cl}_{\mathrm{x}}$ & 1.11 & 22.4 & 73 & 17.9 & 128 \\
\hline
\end{tabular}


WILEY-VCH

\begin{tabular}{lllllllll}
\hline MPMIC $_{60}$ & -4.1 & - & MAPbI $_{3}$ & 1.08 & 20.2 & 64 & 13.8 & 129
\end{tabular}

${ }^{\text {a)} M e a s u r e d ~ s p a c e-c h a r g e ~ l i m i t e d ~ c u r r e n t ~(S C L C) ~ e l e c t r o n ~ m o b i l i t y ~ o f ~ f u l l e r e n e ~ f i l m s ; ~}{ }^{\text {b) }}$ The electron mobility was determined by field-effect transistor measurements; ${ }^{\mathrm{c}}$ Values were obtained from $J-V$ curves in the reverse scan direction.

Table 5. Photovoltaic performances of perovskite-fullerene heterojunction devices.

\begin{tabular}{|c|c|c|c|c|c|}
\hline Device structure & $\overline{V_{\mathrm{oc}}}$ & $J_{\mathrm{sc}}$ & FF & PCE & Ref. \\
\hline & {$[\mathrm{V}]^{\mathrm{a})}$} & {$\left[\mathrm{mA} / \mathrm{cm}^{2}\right]^{\mathrm{a})}$} & {$[\%]^{\mathrm{a})}$} & {$[\%]^{\mathrm{a})}$} & \\
\hline $\mathrm{FTO} / \mathrm{TiO}_{2} / \mathrm{MAPbI}_{3}: \mathrm{PC}_{61} \mathrm{BM} /$ spiro-OMeTAD/Au & 1.086 & 18.0 & 75 & 14.4 & 134 \\
\hline ITO/PEDOT:PSS/MAPbI ${ }_{3}: \mathrm{PC}_{61} \mathrm{BM} / \mathrm{PC}_{61} \mathrm{BM} / \mathrm{Ca} / \mathrm{Al}$ & 0.97 & 20.2 & 82 & 16.0 & 135 \\
\hline ITO/PEDOT:PSS/MAPbI $3: 1 \mathrm{D} \mathrm{PC}_{61} \mathrm{BM} / \mathrm{PC}_{61} \mathrm{BM} / \mathrm{Ca} / \mathrm{Al}$ & 0.90 & 22.88 & 74.3 & 15.30 & 138 \\
\hline $\mathrm{ITO} / \mathrm{TiO}_{2} / \mathrm{ms}-\mathrm{PC}_{61} \mathrm{BM} / \mathrm{MAPbI}_{3} /$ spiro-OMeTAD$/ \mathrm{Au} / \mathrm{Ag}$ & 1.06 & 20.60 & 65 & 14.2 & 139 \\
\hline $\mathrm{FTO} / \mathrm{NiO} / \mathrm{FA}_{0.85} \mathrm{MA}_{0.15} \mathrm{~Pb}\left(\mathrm{I}_{0.85} \mathrm{Br}_{0.85}\right)_{3}: \mathrm{PC}_{61} \mathrm{BM} / \mathrm{PC}_{61} \mathrm{BM} / \mathrm{Nb}: \mathrm{TiO}_{2} /$ & 1.08 & 21.98 & 79 & 18.75 & 140 \\
\hline \multicolumn{6}{|l|}{$\mathrm{Ag}$} \\
\hline FTO/MAPbI ${ }_{3}: \mathrm{IS}-1 /$ spiro-OMeTAD/Au & 1.030 & 16.7 & 68.7 & 11.8 & 141 \\
\hline FTO/MAPbI ${ }_{3}: \mathrm{IS}-2 /$ spiro-OMeTAD/Au & 1.077 & 17.3 & 78 & 14.3 & 141 \\
\hline FTO/MAPbI 3 :PI-2/spiro-OMeTAD/Au & 1.022 & 16.5 & 69.4 & 11.7 & 141 \\
\hline FTO/MAPbI 3 :DPM-6/spiro-OMeTAD/Au & 1.043 & 16.1 & 69.2 & 11.6 & 141 \\
\hline FTO/MAPbI ${ }_{3}: \mathrm{PC}_{61} \mathrm{BM} /$ spiro-OMeTAD/Au & 1.064 & 14.5 & 72.2 & 11.2 & 141 \\
\hline ITO/PEDOT:PSS/MAPbI ${ }_{3}: \mathrm{A}_{10} \mathrm{C}_{60} / \mathrm{PC}_{61} \mathrm{BM} / \mathrm{Al}$ & 0.86 & 18.08 & 86.7 & 13.48 & 142 \\
\hline FTO/PEDOT:PSS/MAPb ${ }_{0.75} \mathrm{Sn}_{0.25} \mathrm{I}_{3}: \mathrm{C}_{60} / \mathrm{PC}_{61} \mathrm{BM} / \mathrm{BCP} / \mathrm{Ag}$ & 0.736 & 23.5 & 79 & 13.7 & 143 \\
\hline
\end{tabular}




\section{WILEY-VCH}

\begin{tabular}{|c|c|c|c|c|c|}
\hline FTO/MAPbI ${ }_{3}: \mathrm{C}_{70} /$ spiro-OMeTAD/Au & 1.059 & 17.4 & 74.1 & 13.6 & 144 \\
\hline $\mathrm{FTO} / \mathrm{TiO}_{2} / \mathrm{mp}-\mathrm{TiO}_{2} / \mathrm{MAPbI}_{3}: \alpha$-bis-PCBM/spiro-OMeTAD/Au & 1.13 & 23.95 & 74 & 20.8 & 145 \\
\hline 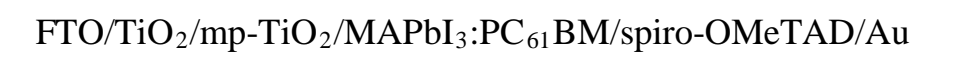 & 1.11 & 23.73 & 73 & 19.9 & 145 \\
\hline ITO/PEDOT:PSS/MAPbI ${ }_{x} \mathrm{Cl}_{3-\mathrm{x}}: \mathrm{C}-\mathrm{PCBSD} / \mathrm{PC}_{61} \mathrm{BM} / \mathrm{Bphen} / \mathrm{Ag}$ & 0.98 & 22.81 & 77 & 17.21 & 146 \\
\hline ITO/Cu:NiO ${ }_{x} / \mathrm{MAPbI}_{3}: \mathrm{DF}-\mathrm{C}_{60} / \mathrm{Bis}_{-} \mathrm{C}_{60} / \mathrm{Ag}$ & 1.09 & 21.08 & 78.7 & 18.11 & 147 \\
\hline
\end{tabular}

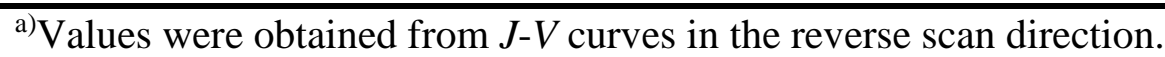

Lin-Long Deng is an associate professor at Pen-Tung Sah Institute of Micro-Nano Science and Technology, Xiamen University. He received his Ph. D. degree in the Department of Chemistry at Xiamen University (2012). After that, he worked as an assistant professor at Xiamen University (2012-2016). In 2017, he works as a visiting researcher in the Department of Physics, Chemistry and Biology (IFM) at Linköping University. His current research interests focus on fullerenes and their photovoltaic applications, particularly organic photovoltaics and perovskite solar cells.

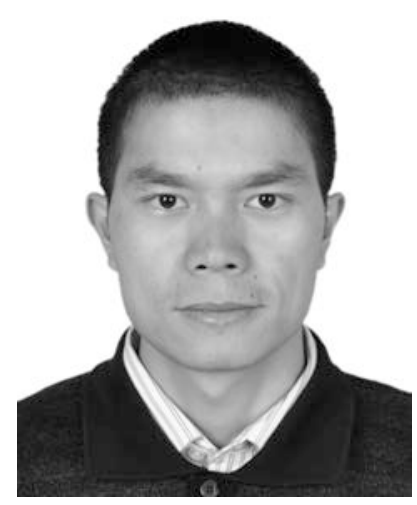


WILEY-VCH 


\section{WILEY-VCH}

Su-Yuan Xie studied chemistry at Fujian Normal University from 1984 to 1988. During 1988-1991, he studied at Central South University and then at Kunming Research Institute of Noble Metal for Master's degree. He joined Professor Lan-Sun Zheng’s group at Xiamen University to pursue his Ph.D. degree in 1996, and worked there after receiving his Ph.D. degree in 1999. As a visiting scientist, he worked at Clemson University during 2003-2005. He is now a professor in chemistry at Xiamen University. His research focuses on synthesis and photovoltaic properties of fullerenes, a family of cage-like molecules typically consisting of hexagons and pentagons.

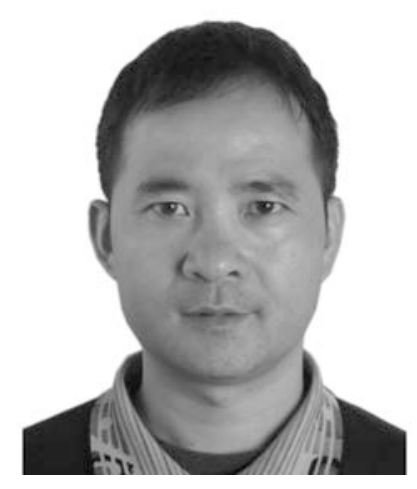




\section{WILEY-VCH}

Feng Gao is an Associate Professor at Linköping University in Sweden. He received his PhD from the University of Cambridge (UK) in 2011, followed by a Marie Curie postdoc fellowship at Linköping University. He received the ERC Starting Grant in 2016. His group currently focuses on the research into solution-processed energy materials and devices, mainly based on semiconducting polymers and metal halide perovskites.

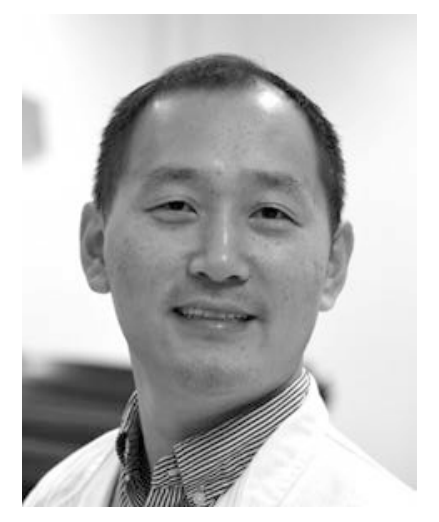




\section{WILEY-VCH}

The application of fullerene materials in perovskite solar cells, such as electron transport layers, interfacial modification layers, and trap state passivators is reviewed. The chemical structure of fullerene that influences performance and function is emphasized. Utilizing hydrophobic, cross-linked, and doped fullerene materials may facilitate the development of perovskite solar cells with high efficiency and excellent long-term stability.

Keyword: Perovskite solar cells, fullerenes, efficiency, hysteresis, stability

L. L. Deng, S. Y. Xie,* Feng Gao *

Fullerene-based Materials for Photovoltaic Applications: Towards Efficient, Hysteresisfree, and Stable Perovskite Solar Cells

ToC figure

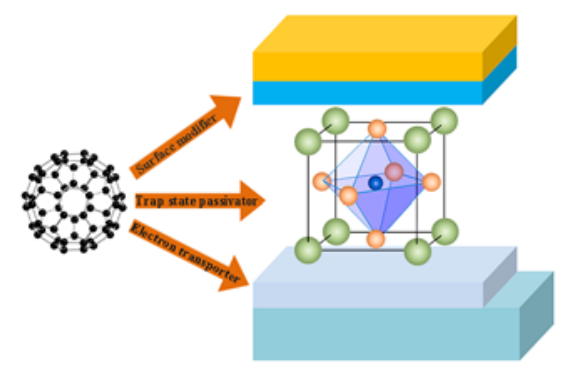

